\title{
Photo-Catalytic Degradation of Volatile Organic Compounds (VOCs) over Titanium Dioxide Thin Film
}

\author{
Wenjun Liang, Jian Li and Hong He \\ Additional information is available at the end of the chapter
}

http://dx.doi.org/10.5772/48099

\section{Introduction}

Volatile organic compounds (VOCs) are emitted as gases from certain solids or liquids. VOCs include a variety of chemicals, some of which may have short- and long-term adverse health effects. Concentrations of many VOCs are consistently higher indoors (up to ten times higher) than outdoors.

The control of VOCs in the atmosphere is a major environmental problem. The traditional methods of VOCs removal such as absorption, adsorption, or incineration, which are referred to the new environmental condition have many technical and economical disadvantages. So in recent years, some new technologies called advanced oxidation processes (AOPs), such as biological process, photo-catalysis process or plasma technology, are paid more and more attention.

Advanced oxidation processes (AOPs) are efficient novel methods useful to accelerate the non-selective oxidation and thus the destruction of a wide range of organic substances resistant to conventional technologies. AOPs are based on physicochemical processes that produce in situ powerful transitory species, principally hydroxyl radicals, by using chemical and/or other forms of energy, and have a high efficiency for organic matter oxidation.

Among AOPs, photocatalysis has demonstrated to be very effective to treat pollutants both in gas and in liquid phase. The photo-excitation of semiconductor particles $\left(\mathrm{TiO}_{2}\right)$ promotes an electron from the valence band to the conduction band thus leaving an electron deficiency or hole in the valence band; in this way, electron/hole pairs are generated. Both reductive and oxidative processes can occur at/or near the surface of the photo-excited semiconductor particle. 
Photocatalytic degradation of VOCs on UV-illuminated titanium dioxide $\left(\mathrm{TiO}_{2}\right)$ is proposed as an alternative advanced oxidation process for the purification of water and air. Heterogeneous photo-catalysis using $\mathrm{TiO}_{2}$ has several attractions: $\mathrm{TiO}_{2}$ is relatively inexpensive, it dispenses with the use of other coadjutant reagents, it shows efficient destruction of toxic contaminants, it operates at ambient temperature and pressure, and the reaction products are usually $\mathrm{CO}_{2}$ and $\mathrm{H}_{2} \mathrm{O}$, or $\mathrm{HCl}$, in the case of chlorinated organic compounds. Decomposition path of VOCs with $\mathrm{UV} / \mathrm{TiO}_{2}$ or $\mathrm{UV} / \mathrm{TiO}_{2} /$ doped ions is shown in Fig. 1. However, the formations of by-products, such as $\mathrm{CO}$, carbonic acid and coke-like substances, were often observed. These by-product formations are due to low degradation rate of intermediate compounds that are formed by the partial oxidation of VOCs. In order to improve the VOC degradation rate, some authors reported on the enhancement of VOC degradation through the addition of anions (dopant $=\mathrm{S}, \mathrm{N}, \mathrm{P}$, etc), cations (dopant $=\mathrm{Pt}, \mathrm{Cu}$, $\mathrm{Mg}$, etc), polymers or co-doped with several ions on $\mathrm{TiO}_{2}$, while the difference between doping agents has not been discussed yet.

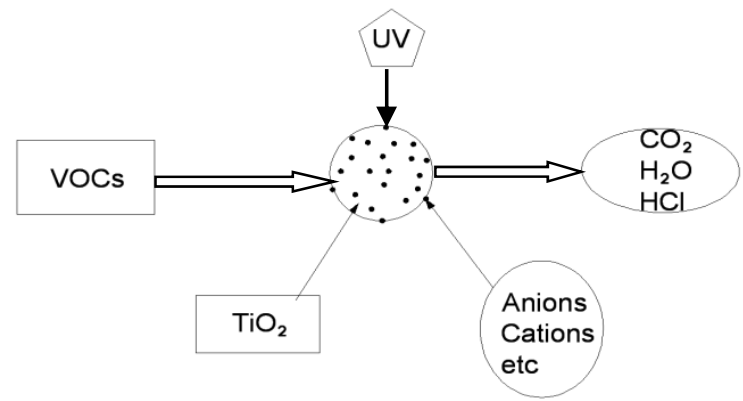

Figure 1. Decomposition path of VOCs with $\mathrm{UV} / \mathrm{TiO}_{2}$.

In this chapter, toluene, p-xylene, acetone and formaldehyde were chosen as the model VOCs because they were regarded as representative indoor VOCs for determining the effectiveness and capacity of gas-phase air filtration equipment for indoor air applications, the photo-catalytic degradation characters of them by $\mathrm{TiO}_{2} / \mathrm{UV}, \mathrm{TiO}_{2} / \mathrm{doped} \mathrm{Ag} / \mathrm{UV}$ and $\mathrm{TiO}_{2} /$ doped $\mathrm{Ce} / \mathrm{UV}$ was tested and compared. The effects of hydrogen peroxide, initial concentration, gas temperature, relative humidity of air stream, oxygen concentration, gas flow rate, UV light wavelength and photo-catalyst amount on decomposition of the pollutants by $\mathrm{TiO}_{2} / \mathrm{UV}$ were analyzed simultaneously. Furthermore, the mechanism of titania-assisted photo-catalytic degradation was analyzed, and the end product of the reaction using GC-MS analysis was also performed.

\section{Materials and methods}

\subsection{Chemicals and experimental set-up}

Acetone, toluene, p-xylene and formaldehyde used in our experiment was analytical reagent. The $\mathrm{TiO}_{2}$ photocatalyst was prepared with $100 \%$ anatase using the sol-gel method, 
and immobilized as a film (thickness $0.2 \mathrm{~mm}$ ) on glass springs. Ethanol, tetrabutyl orthotitanate, diethanolamine, N,N-dimethylformamide and polyethylene glycol used as raw materials for photocatalyst preparation were of analytical grade and utilized without further purification. $\mathrm{AgNO}_{3}, \mathrm{Ce}\left(\mathrm{NO}_{3}\right)_{3} \bullet 6 \mathrm{H}_{2} \mathrm{O}$ were used as $\mathrm{Ag}$ or Ce source for modified $\mathrm{TiO}_{2}$ samples. Deionized water was used throughout the study.

A schematic diagram of the experimental system for photo-oxidation is shown in Fig. 2. The experiments were performed in a cylindrical photo-catalytic reactor with inner diameter $18.0 \mathrm{~mm}$. A germicidal lamp (wavelength range 200-300 $\mathrm{nm}$ ) with the maximum light intensity at $254 \mathrm{~nm}$ was installed in the open central region. The desired amount of representative sample, that is acetone, toluene, $\mathrm{p}$-xylene or formaldehyde, was injected into the obturator. Then, the photo-catalytic degradation was performed by transporting the gas across the photo-catalyst continuously when UV lamp was turned on. Glass spring coated by a $\mathrm{TiO}_{2}$ thin film was filled around the lamp. In whole experiment, humidity was controlled and adjusted with vapour. In some experiments it was replaced with a $15 \mathrm{~W}$ black-light lamp with a maximum light intensity output at $365 \mathrm{~nm}$. After a stabilized period of about $3 \mathrm{~h}$, the pollutant concentrations in the outlet gas became the same as in the inlet gas, and the experiment was started by turning on the UV lamp. Relative humidity of the reactor was detected with humidity meter. Oxygen concentration was controlled with oxygen detector.

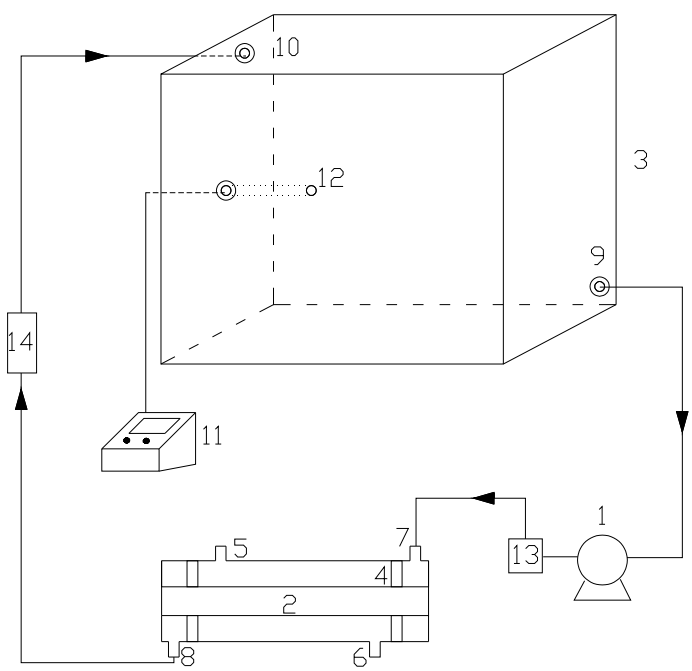

Figure 2. Schematic diagram of experimental set-up. 1- Minitype circulation pump; 2 - Germicidal lamp; 3 - Obturator (airproof tank, 125 L); 4 - Lacunaris clapboard; 5, 6 - Sampling spots; 7-10 - Inlet \& Outlet; 11 - Temperature-humidity detector; 12 - Probe; 13 - Gas heated container; 14 - Humidity controller. 


\subsection{Photo-catalyst preparation}

Fig. 3 shows the schematic flow-chart of the experimental procedure. $\mathrm{TiO}_{2}$ precursor sols were prepared by adding tetrabutylorthotitanate $(400 \mathrm{~mL})$ into ethanol $(960 \mathrm{~mL})$ at room temperature. Then diethanolamine $(69.1 \mathrm{~mL})$ was added, and the mixture stirred for $2 \mathrm{hr}$. Subsequently, ethanol $(120 \mathrm{~mL})$, deionized water $(25.2 \mathrm{~g}), 5 \mathrm{wt} \% \mathrm{AgNO}_{3}$ or $\mathrm{Ce}\left(\mathrm{NO}_{3}\right)_{3}$ were added dropwise to the solution. After stirring for $15 \mathrm{~min}, \mathrm{~N}, \mathrm{~N}$-dimethylformamide (16.8 $\mathrm{mL}$ ) was added. This reduced surface tension and made a smooth coating of the thin film on the carrier. The solution was then left to rest for $24 \mathrm{hr}$. Finally, polyethylene glycol (4.32 g) dissolved in ethanol $(120 \mathrm{~mL})$ at $50{ }^{\circ} \mathrm{C}$ was added dropwise to the solution. The final solution was left to sit for $12 \mathrm{hr}$, after which the $\mathrm{TiO}_{2}$ gel had formed. The prepared mixture could remain stable for months at ambient temperature. Thin film $\mathrm{TiO}_{2}$ photocatalyst was formed by dip-coating with a velocity of $5 \mathrm{~cm} / \mathrm{s}$. Glass springs were selected as the photocatalyst carrier due to their excellent transparency and long light diffusion distance. Fig. 4 was the sketch of glass spring structure. These were immersed in the $\mathrm{TiO}_{2}$ gel mixture, and then dried at room temperature. This was followed by calcination at $500{ }^{\circ} \mathrm{C}$ in a muffle furnace for $2 \mathrm{hr}$. The glass springs were coated repeatedly (total of five times) using this method to form a thin $\mathrm{TiO}_{2}$ photocatalyst film. The $\mathrm{TiO}_{2}$ film was very stable and durable, and no loss was observed during its application.

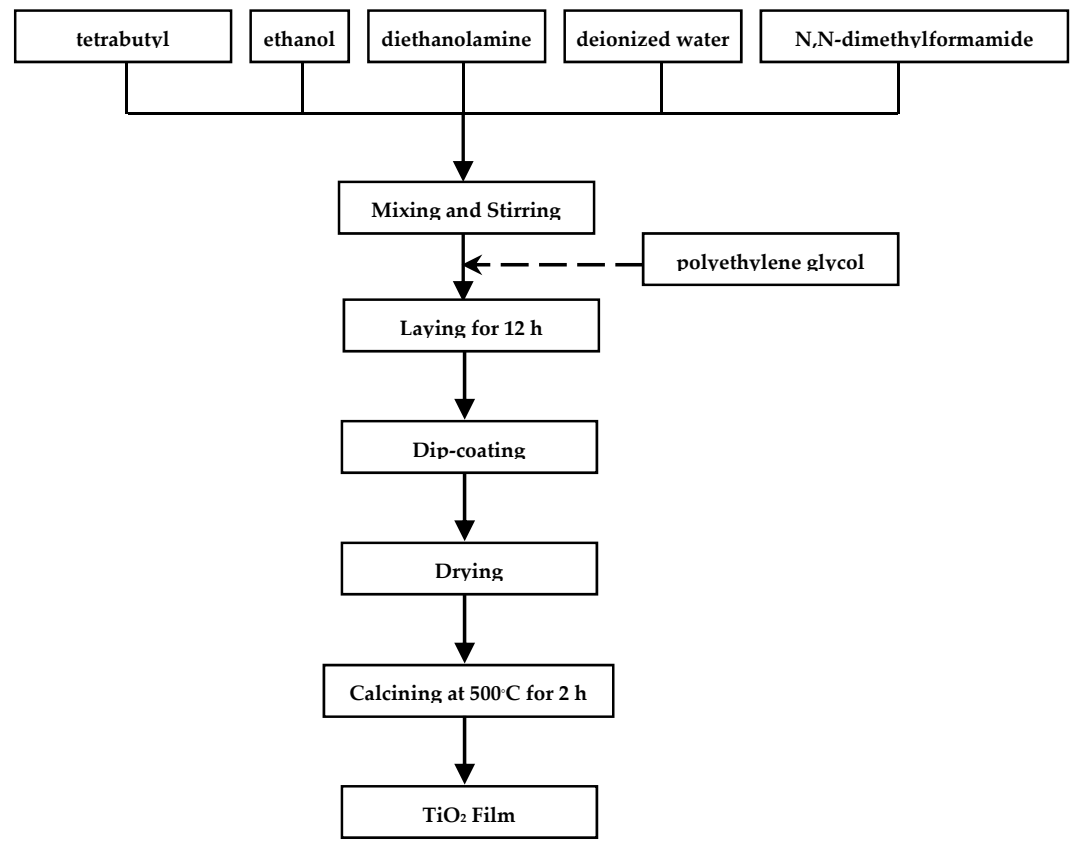

Figure 3. Flowchart of photo-catalyst preparation. 


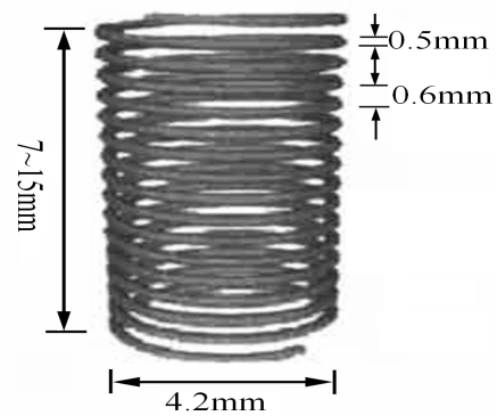

Figure 4. Sketch of glass spring structure.

\subsection{Analytical methods}

The concentrations of acetone, toluene, and p-xylene were analyzed by a gas chromatograph (Model GC-14C, Shimadzu, Japan) with a flame ionization detector (FID). The oven temperature was held at $60{ }^{\circ} \mathrm{C}$ and detector temperature maintained constant at $100{ }^{\circ} \mathrm{C}$. The end products of the reaction were detected by GC-MS. GC-MS analysis was conducted using an HP 6890N GC and HP 5973i MSD. A HP-5 capillary column $(30 \mathrm{~m} \times 0.32 \mathrm{~mm}$ ID) was used isothermally at $60^{\circ} \mathrm{C}$. The carrier gas (helium) flow-rate was $30 \mathrm{~cm} / \mathrm{s}$, and the injector and detector temperatures were $150^{\circ} \mathrm{C}$ and $280^{\circ} \mathrm{C}$, respectively. Intermediate products analysis was done by EI mode and full scan. Formaldehyde concentration in gas stream was determined by acetylacetone spectrophotometric method. HCHO absorbed by deionized water in acetic acideammonium acetate solution would react with acetylacetone to form a steady yellow compound. HCHO concentration in the gas stream was then determined by measuring light absorbance at $413 \mathrm{~nm}$ with a spectrophotometer (UV/Vis 722). Temperature and humidity were measured with a temperature-humidity detector (Model LZB-10WB, Beijing Yijie Automatic Equipment Ltd., China).

The characteristics of the immobilized nano-structured $\mathrm{TiO}_{2}$ thin film were analyzed by field-emission scanning electron microscopy (FE-SEM, Model JSM 6700F, JEOL, Japan) and X-ray diffractometry (XRD, Rigaku, D-max- $\gamma \mathrm{A}$ XRD with $\mathrm{Cu} K \alpha$ radiation, $\lambda=1.54178 \AA$ ). The surface area of the $\mathrm{TiO}_{2}$ film was also analyzed using gas adsorption principles (Detected by Micromeritics, American Quantachrome Co., NOVA 1000). The synthesized samples had a BET surface area of $56.3 \mathrm{~m}^{2} / \mathrm{g}$, compared with Degussa P25 $\mathrm{TiO}_{2}$ with a surface area of $50.2 \mathrm{~m}^{2} / \mathrm{g}$.

The degradation rates (\%) of acetone, toluene, p-xylene and formaldehyde were calculated as follows:

$$
\eta=\frac{C_{i}-C_{o}}{C_{i}} \times 100 \%
$$

where $C_{i}$ is the inlet concentration, and $C_{o}$ is the outlet concentration at steady state. 


\section{Results and discussion}

\subsection{SEM and XRD Images of the Photocatalyst}

FE-SEM analysis of the particle size and shape of the synthesized $\mathrm{TiO}_{2}$ sample showed it consisted of uniform nano-particles (Fig. 5). However, some cracks were found on the surface. A major contributor to these cracks could be the greater surface tension resulting from the small diameter $(0.5 \mathrm{~mm})$ of the glass springs and the high-temperature sintering process. In further experiments, we decreased the temperature from $500{ }^{\circ} \mathrm{C}$ to $450{ }^{\circ} \mathrm{C}$. At the lower temperature, there were fewer cracks on the surface but they were not eliminated completely.
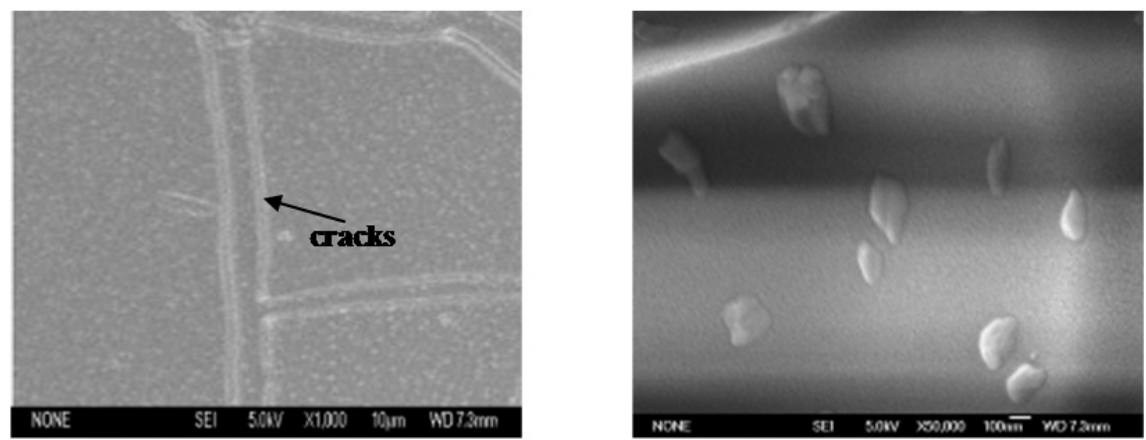

Figure 5. SEM photographs and macroscopic morphology of the $\mathrm{TiO}_{2}$ thin film coated on a glass spring.

The left and right photographs were taken at 1000× and $50000 \times$ magnification, respectively.

According to Scherrer's equation (Eq. 2) and XRD patterns, the particle size of $\mathrm{TiO}_{2}$ (D) was calculated to be $35 \mathrm{~nm}$.

$$
D=k \lambda / \beta \cos \theta
$$

The crystalline phase of the $\mathrm{TiO}_{2}$ catalyst was analyzed by XRD (Fig. 6). All the diffraction peaks in the XRD pattern could be assigned to tetragonal anatase $\mathrm{TiO}_{2}$, with lattice constants of $\mathrm{a}=0.3785 \mathrm{~nm}, \mathrm{~b}=0.3785 \mathrm{~nm}$, and $\mathrm{c}=0.9514 \mathrm{~nm}$.

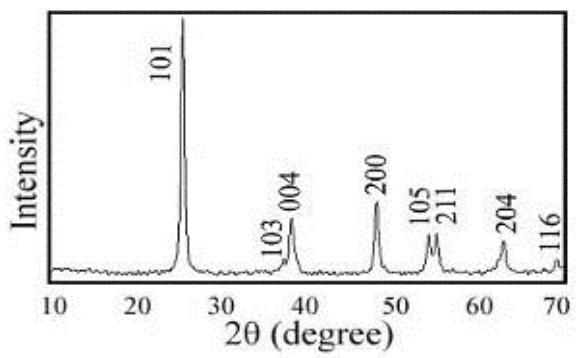

Figure 6. XRD spectrum of anatase crystalline phase of the $\mathrm{TiO}_{2}$ catalyst 


\subsection{Effect of doped $\mathrm{Ag} / \mathrm{TiO}_{2}$ or $\mathrm{Ce} / \mathrm{TiO}_{2}$ on decomposition of VOCs}

The characters of catalyst are important for the degradation of VOCs. Fig. 7 illustrates the degradation rates of acetone, toluene, and p-xylene (ATP) as functions of irradiation time when pure $\mathrm{TiO}_{2}, \mathrm{Ag}-\mathrm{TiO}_{2}$ and $\mathrm{Ce}-\mathrm{TiO}_{2}$ were used. As controls, blank experiments in the absence of $\mathrm{TiO}_{2}$ had been studied. The results corresponded to the flow-rate of $1 \mathrm{~L} / \mathrm{min}$, initial concentration of $0.1 \mathrm{~mol} / \mathrm{m}^{3}$ and relative humidity of $35 \%$. It was found that all the conversions of ATP in the $\mathrm{TiO}_{2} / \mathrm{UV}, \mathrm{Ag}-\mathrm{TiO}_{2} / \mathrm{UV}$ and $\mathrm{Ce}-\mathrm{TiO}_{2} / \mathrm{UV}$ processes were increased with irradiation time. Table 1 shows the degradation rates for both catalysts after 8 -h photocatalytic reaction. It can be seen from Fig. 7 and Table 1 that the doping of silver or cerium ions could improve the photo-activity of $\mathrm{TiO}_{2}$ effectively. Furthermore, the degradation character of the photo-catalyst was in the order $\mathrm{Ce}-\mathrm{TiO}_{2}>\mathrm{Ag}-\mathrm{TiO}_{2}>\mathrm{TiO}_{2}$. Besides, the results of blank experiments in the absence of $\mathrm{TiO}_{2}$ showed that the removal efficiency of ATP was very low. For example, the removal efficiency of acetone was merely $6.3 \%$ after $8 \mathrm{~h}$ and lower than $46.5 \%$ for pure $\mathrm{TiO}_{2}$, which means that $\mathrm{TiO}_{2}$ plays an important role in photo-catalytic reaction.

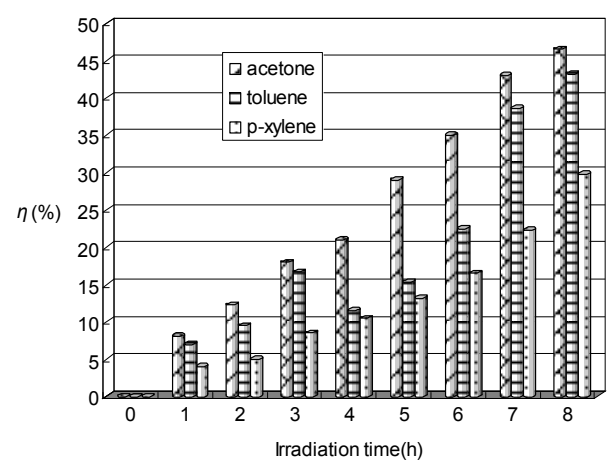

$\left(\mathrm{TiO}_{2}\right)$

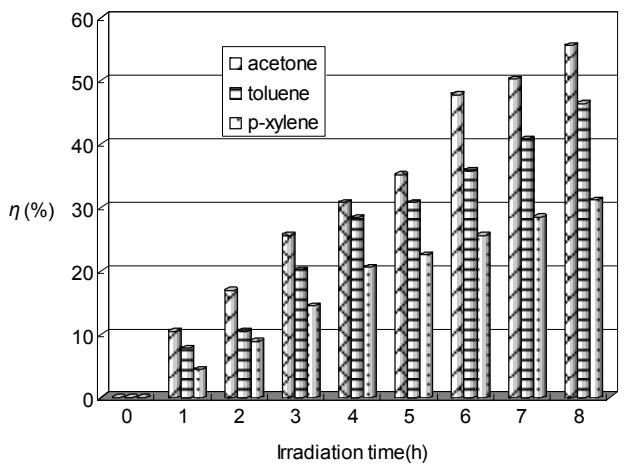

$\left(\mathrm{Ag}-\mathrm{TiO}_{2}, 5 \mathrm{wt} \%\right)$ 


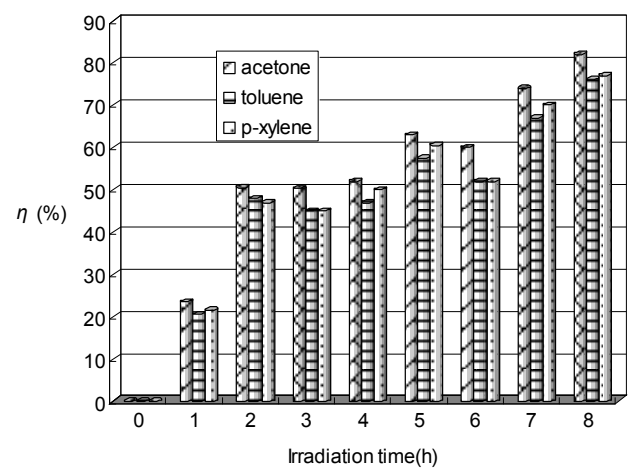

$\left(\mathrm{Ce}-\mathrm{TiO}_{2}, 5 \mathrm{wt} \%\right)$

Figure 7. Effect of doped $\mathrm{Ag} / \mathrm{Ce} / \mathrm{TiO}_{2}$ on decomposition of ATP.

\begin{tabular}{cccc}
\hline Catalyst & $\mathrm{TiO}_{2}$ & $\mathrm{Ag}-\mathrm{TiO}_{2}$ & $\mathrm{Ce}-\mathrm{TiO}_{2}$ \\
\hline$\eta$ (acetone, \%) & 46.5 & 55.5 & 82.0 \\
$\eta$ (toluene, \%) & 43.2 & 46.4 & 76.2 \\
$\eta(p$-xylene, $\%)$ & 29.8 & 31.2 & 77.8 \\
\hline
\end{tabular}

Table 1. ATP degradation rates for different catalysts after $8 \mathrm{hrs}$.

Fig. 8 illustrated the effect of doped $\mathrm{Ag} / \mathrm{Ce} / \mathrm{TiO}_{2}$ on decomposition of $\mathrm{HCHO}$. The conditions were as follows: flow-rate of $3 \mathrm{~L} / \mathrm{min}$, initial concentration of $0.1 \mathrm{mg} / \mathrm{m}^{3}$, relative humidity of $35 \%$. It was found that conversions of $\mathrm{HCHO}$ in the $\mathrm{TiO}_{2} / \mathrm{UV}, \mathrm{Ag}-\mathrm{TiO}_{2} / \mathrm{UV}$ and $\mathrm{Ce}-\mathrm{TiO}_{2} / \mathrm{UV}$ processes were increased with irradiation time. It could be seen that the doping of silver or cerium ions could improve the photo-activity of $\mathrm{TiO}_{2}$ effectively. Furthermore, the degradation character of the photo-catalyst was in the order $\mathrm{Ce}-\mathrm{TiO}_{2}>\mathrm{Ag}-\mathrm{TiO}_{2}>\mathrm{TiO}_{2}$.

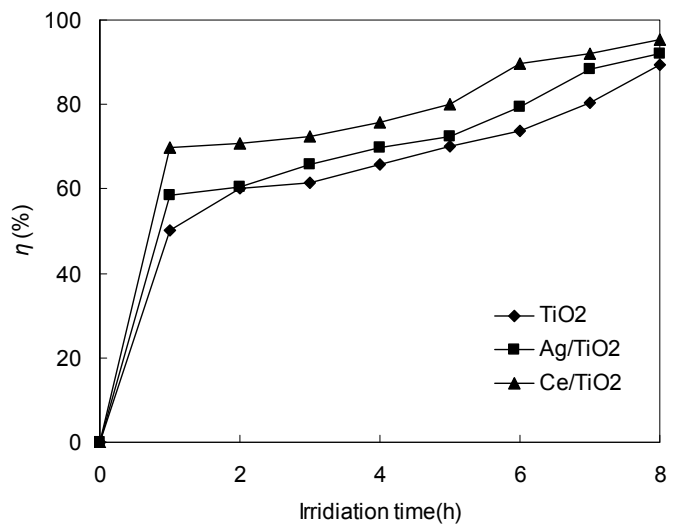

Figure 8. Effect of doped $\mathrm{Ag} / \mathrm{Ce} / \mathrm{TiO}_{2}$ on decomposition of $\mathrm{HCHO}$. 
The reason was as follows: Ag/Ce doping could narrow the band gap. The narrower band gap will facilitate excitation of an electron from the valence band to the conduction band in the doped $\mathrm{TiO}_{2}$, thus increasing the photo-catalytic activity of the material. At the same time, silver or cerium species could create a charge imbalance, vacancies and unsaturated chemical bonds on the catalyst surface. It will lead to the increase of chemisorbed oxygen on the surface. Surface chemisorbed oxygen has been reported to be the most active oxygen, and plays an important role in oxidation reaction. Herein, silver or cerium modified $\mathrm{TiO}_{2}$ might have better activity for the oxidation of VOCs. Furthermore, samples after Ag/Ce doping treatment showed a slight change of colour from white to yellowish.

The photo-catalytic activity of $\mathrm{Ce}-\mathrm{TiO}_{2}$ in the oxidative degradation of VOCs being higher than that of $\mathrm{Ag}-\mathrm{TiO}_{2}$ may be explained as follows: Compared to $\mathrm{Ag}$, Ce doping serves as an electron trap in the reaction because of its varied valences and special $4 \mathrm{f}$ level. $\mathrm{For}_{\mathrm{Ce}}{ }^{3+}-\mathrm{TiO}_{2}$, the Ce $4 \mathrm{f}$ level plays an important role in interfacial charge transfer and elimination of electron-hole recombination. So, Ce doping could enhance the electron-hole separation and the decomposition rate of VOCs could be elevated. Moreover, the valence electrons of $\mathrm{TiO}_{2}$ catalyst are excited to the conduction band by UV light, and after various other events, electrons on the $\mathrm{TiO}_{2}$ particle surface are scavenged by the molecular oxygen to produce reactive oxygen radicals. Furthermore, redox reactions between the pollutant molecules and reactive oxygen radicals happened, VOC molecules were turned into harmless inorganic compounds, such as $\mathrm{CO}_{2}$ and $\mathrm{H}_{2} \mathrm{O}$ at the end.

\subsection{Effect of Hydrogen Peroxide}

Hydrogen peroxide is considered to have two functions in the photo-catalytic degradation. It accepts a photo-generated conduction band electron, thus promoting the charge separation, and it also forms $\mathrm{OH} \bullet$. The addition of $\mathrm{H}_{2} \mathrm{O}_{2}$ increases the concentration of $\mathrm{OH} \bullet$ radicals since it inhibits the electron-hole recombination.

Experiments were conducted to evaluate the effect of $\mathrm{H}_{2} \mathrm{O}_{2}$ on the toluene/p-xylene photodegradation. The conditions were as follows: flow rate of $1 \mathrm{~L} / \mathrm{min}$, initial concentration of 0.1 $\mathrm{mol} / \mathrm{m}^{3}$, relative humidity of $35 \%$, and photo-catalyst of pure $\mathrm{TiO}_{2}$. As shown in Fig. 9, the removal efficiency of toluene or p-xylene increased with reaction time.

In the first $3 \mathrm{~h}$, the degradation rate of toluene or p-xylene without $\mathrm{H}_{2} \mathrm{O}_{2}$ was higher because of the competitive adsorption between toluene or p-xylene molecules and hydrogen peroxide. Then, more reactants and/or radical molecules were produced during the photochemistry course, which led to the improvement of toluene or $\mathrm{p}$-xylene decomposition. The final degradation rates of toluene and p-xylene with $\mathrm{H}_{2} \mathrm{O}_{2}$ were up to 97.1 and $95.4 \%$ after 8 $h$, respectively.

The degradation of acetone was studied with and without hydrogen peroxide (Fig. 10). Overall, the acetone removal efficiency increased with reaction time. Initially, the degradation rate of without $\mathrm{H}_{2} \mathrm{O}_{2}$ was higher than that of with $\mathrm{H}_{2} \mathrm{O}_{2}$ because of competitive adsorption between acetone and hydrogen peroxide after hydrogen peroxide addition to the 


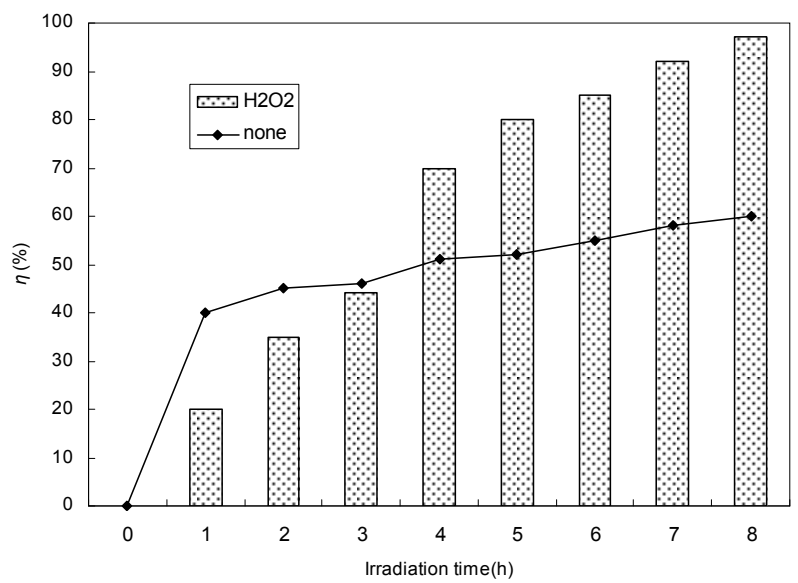

(Toluene)

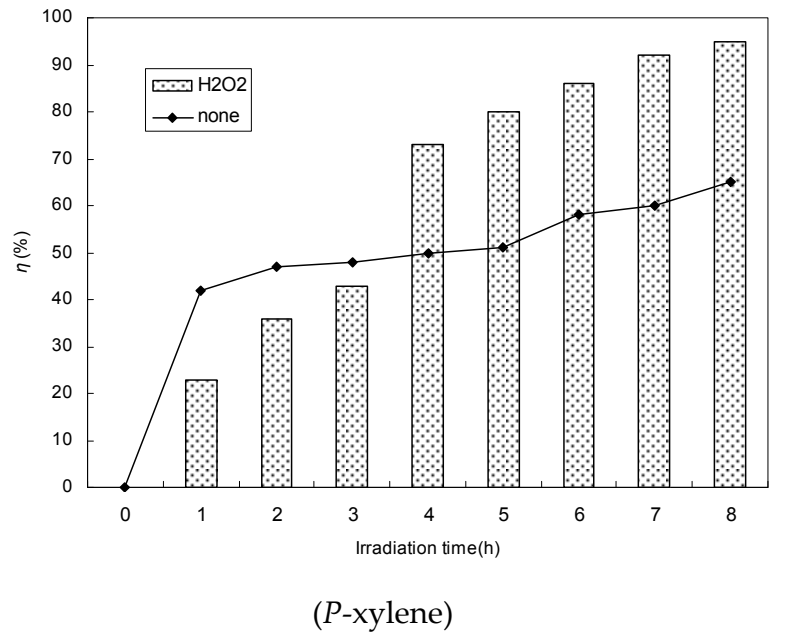

Figure 9. Effect of toluene/p-xylene degradation on hydrogen peroxide.

sample chamber (10 $\mathrm{mL}$ per $30 \mathrm{~min}, 30 \% \mathrm{H}_{2} \mathrm{O}_{2}, \mathrm{RH} 35 \%$ ). As the reactants and/or byproducts accumulated on the catalyst, and there was no new super-oxidation supplied, the catalyst deactivated and the degradation rate increased slowly after $2 \mathrm{hr}$. Hydroxyl radicals were produced due to the presence of hydrogen peroxide (Eq. 3). This decreased recombination of electron-hole pairs, and consequently the final acetone degradation rate was up to $91.8 \%$ after $8 \mathrm{hr}$. Consumption of hydroxyl radical likely played an important role in deactivation of the catalyst. An appropriate volume of hydrogen peroxide could enhance the degradation rate, while too much could decrease the degradation rate (Eq. 4). 


$$
\begin{gathered}
\mathrm{H}_{2} \mathrm{O}_{2}+\mathrm{e}^{-} \rightarrow \cdot \mathrm{OH}+\mathrm{OH}^{-} \\
\mathrm{H}_{2} \mathrm{O}_{2}+\cdot \mathrm{OH} \rightarrow \mathrm{H}_{2} \mathrm{O}+\mathrm{HO}_{2} \cdot
\end{gathered}
$$

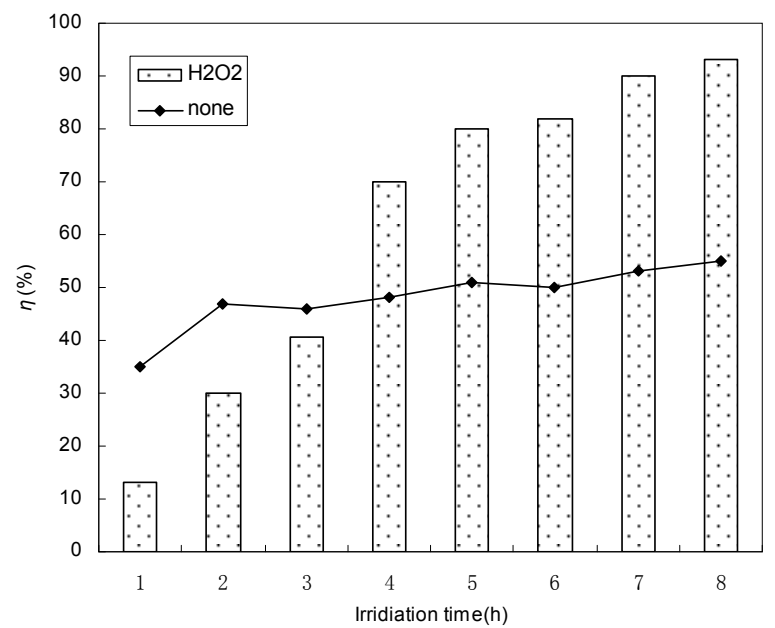

Figure 10. Effect of acetone degradation on hydrogen peroxide.

During deactivation the catalyst color in process without $\mathrm{H}_{2} \mathrm{O}_{2}$ changed from light white to khaki, while with $\mathrm{H}_{2} \mathrm{O}_{2}$ was light khaki. This suggests catalyst deactivation in process without $\mathrm{H}_{2} \mathrm{O}_{2}$ was more extensive than in with $\mathrm{H}_{2} \mathrm{O}_{2}$. Moreover, the change in catalyst color after the reaction indicates that the reaction occurred in the surface of the catalyst. After sintering at $390{ }^{\circ} \mathrm{C}$ for $1 \mathrm{~h}$ the catalyst recovered its original color. This again suggests that catalyst deactivation was due to the accumulation of reactants and by-products on the catalyst surface, which impeded degradation reactions. To compare the performance of $\mathrm{H}_{2} \mathrm{O}_{2} / \mathrm{UV}$, we evaluated the potential of acetone degradation by $\mathrm{H}_{2} \mathrm{O}_{2}$ alone. The concentration of acetone remained almost the same over $8 \mathrm{~h}$. Consequently, we concluded that $\mathrm{H}_{2} \mathrm{O}_{2}$ alone could not remove the VOCs.

\subsection{Effect of initial concentration}

In order to discuss the effect of VOCs initial concentration on photo-catalytic degradation rates, we investigated the removal efficiency of ATP and $\mathrm{HCHO}$ under different initial concentrations. The ATP concentrations in the experiment ranged between $0.05-0.3 \mathrm{~mol} / \mathrm{m}^{3}$. The conditions were as follows: gas flow-rate of $1 \mathrm{~L} / \mathrm{min}$, relative humidity of $35 \%$, Cedoped $\mathrm{TiO}_{2}$ as photo-catalyst, and irradiation time of $8 \mathrm{hr}$. The results showed that the photo-catalytic degradation rates decreased with increasing ATP initial concentration, just illustrated in Fig. 11. Based on the Langmuir-Hinshelwood equation, the degradation rate decreased with increasing initial concentration while the absolute amount of degraded 
pollutants may increase. At higher initial concentration, the UV light might be absorbed by gaseous pollutants rather than the $\mathrm{TiO}_{2}$ particles, which led to the reduction of the photodegradation efficiency. Moreover, at different initial concentrations, acetone was easiest to be destructed, while p-xylene was difficult to be removed among ATP from gas flow.

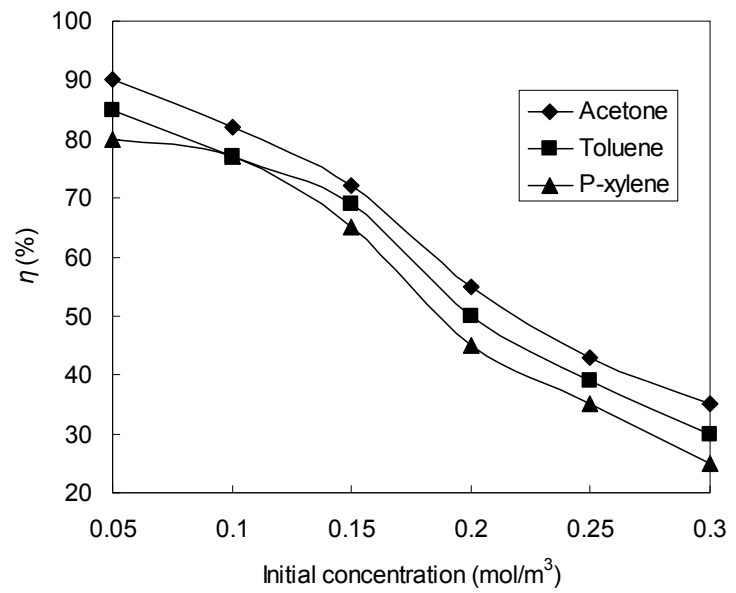

Figure 11. Effect of ATP initial concentration on the photo-catalysis of ATP by $\mathrm{TiO}_{2}$.

As a main indoor pollutant, the indoor formaldehyde concentration is usually below 0.5 ppmv. It is worth discussing whether the low level of indoor $\mathrm{HCHO}$ can be decreased to a value below $0.1 \mathrm{mg} / \mathrm{m}^{3}$ (specified in the indoor air quality standard of China). So in our experiment, the $\mathrm{HCHO}$ concentrations in the experiment ranged between $0.1-0.5 \mathrm{mg} / \mathrm{m}^{3}$. The conditions were as follows: relative humidity of $35 \%$, Ce-doped $\mathrm{TiO}_{2}$ as photo-catalyst, and irradiation time of $120 \mathrm{~min}$. The results showed that the photo-catalytic degradation rates decreased with increasing HCHO initial concentration, just illustrated in Fig. 12.

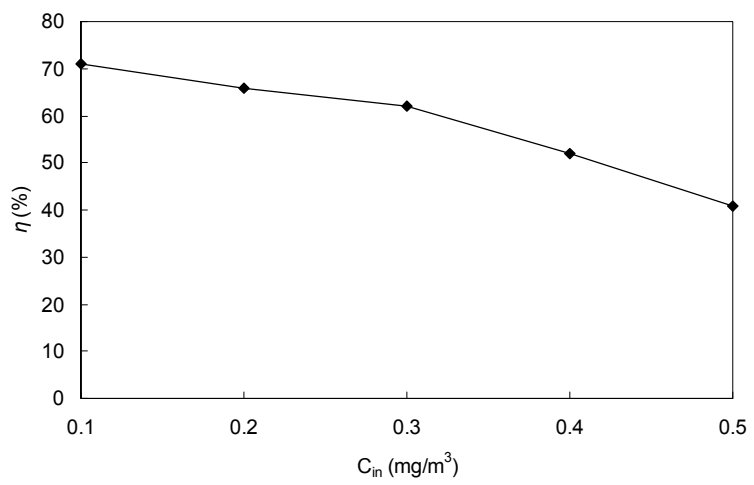

Figure 12. Effect of initial $\mathrm{HCHO}$ concentration on $\mathrm{HCHO}$ degradation by $\mathrm{TiO}_{2}$. 
In gas-phase photo-catalyst, collision frequency between radicals and $\mathrm{HCHO}$ affected the removal efficiency. When formaldehyde molecule reaches to the catalyst surface, the photo oxidation will occur. At higher initial concentration, the UV light might be absorbed by gaseous pollutants rather than the $\mathrm{TiO}_{2}$ particles, which led to the reduction of the photodegradation efficiency.

\subsection{Effect of UV Light Wavelength}

In order to investigate the influence of the UV intensity on the photo-catalytic efficiency, the experiments were performed using two lamp configurations (254 and $365 \mathrm{~nm}$ ). The effect of UV light wavelength on the efficiency of $\mathrm{HCHO}$ degradation is shown in Fig. 13. Just shown in Fig.13, $254 \mathrm{~nm}$ UV light provided more effective HCHO photo-degradation than $365 \mathrm{~nm}$ UV light.

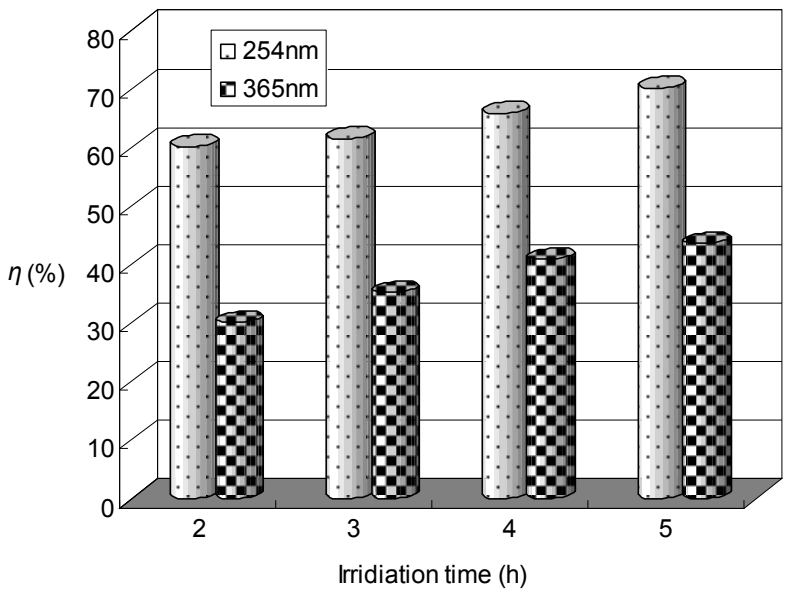

Figure 13. Effect of UV light wavelength on $\mathrm{HCHO}$ degradation.

The effect of UV light wavelength on the efficiency of ATP degradation is shown in Fig.14. $254 \mathrm{~nm}$ UV light provided more effective ATP photodegradation than $365 \mathrm{~nm}$ UV light. Degradation of ATP in the $\mathrm{UV} / \mathrm{TiO}_{2}$ process followed the same trend. 


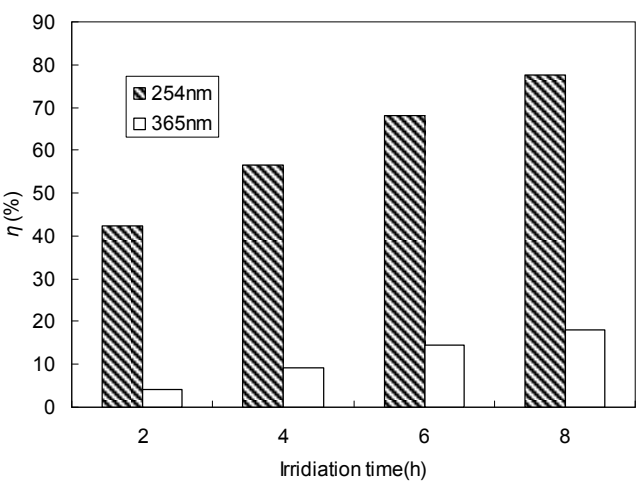

(a) Acetone

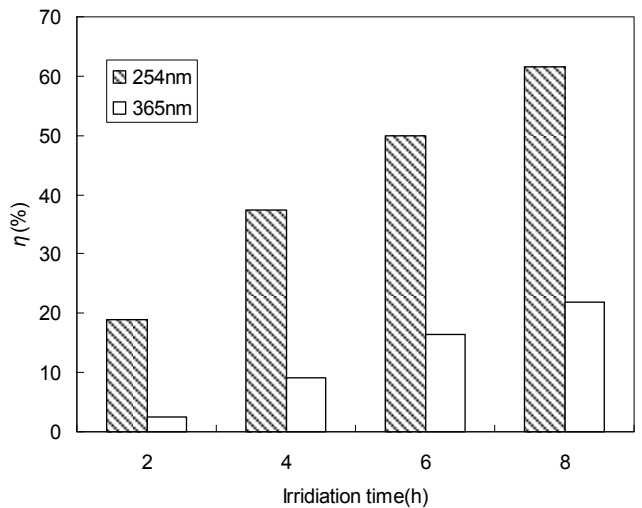

(b) Toluene

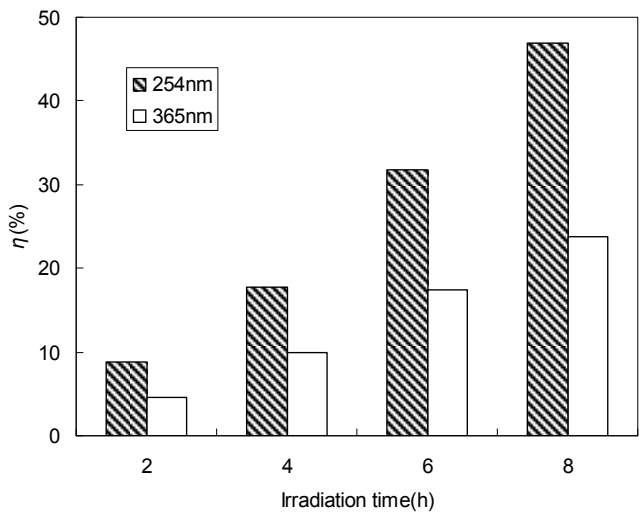

(c) P-xylene

Figure 14. Effect of $\mathrm{UV}$ wavelength on degradation of acetone, toluene, and p-xylene by $\mathrm{TiO}_{2} / \mathrm{UV}$ processes. 
The different results obtained with 254 and $365 \mathrm{~nm}$ UV lamps were mainly due to the stronger UV irradiation from the $254 \mathrm{~nm}$ lamp (about $58 \mathrm{~W} / \mathrm{m}^{2}$ on its surface) than that from the $365 \mathrm{~nm}$ lamp ( $30 \mathrm{~W} / \mathrm{m}^{2}$ on its surface). This illustrates that the $254 \mathrm{~nm}$ UV lamp irradiated photons with higher energy, which led to more efficient degradation with $\mathrm{TiO}_{2} / \mathrm{UV}$.

\subsection{Effect of gas flow rate}

The effect of gas flow rate on ATP degradation was studied at an initial concentration of 0.1 $\mathrm{mol} / \mathrm{m}^{3}$ and relative humidity of $35 \%$, just as shown in Fig. 15 . When the flow rate was increased from 3-9 L/min, degradation of toluene and acetone decreased. With a flow rate $>3 \mathrm{~L} / \mathrm{min}$ the reactants have shorter residence time on the photocatalyst surface and consequently do not bind to the active sites. In general, an increase in gas flow rate results in two antagonistic effects. These are a decrease in residence time within the photocatalytic reactor, and an increase in the mass transfer rate. In our opinion, the decrease in degradation with increasing gas flow rate showed that the residence time of pollutant molecules with $\mathrm{TiO}_{2}$ is an important factor. However, the degradation rate at $1 \mathrm{~L} / \mathrm{min}$ was the lowest. This was due to adsorption of active species on the catalyst, which led to a decrease in the reaction between pollutant molecules and active species. For p-xylene, the degradation rate was the highest when the flow rate was $7 \mathrm{~L} / \mathrm{min}$. From these results it can be concluded that gas flow rate remarkably influences the degradation rate. While both toluene and p-xylene are aromatic hydrocarbons, toluene is an unsymmetrical molecule and p-xylene is symmetrical. Consequently, the adsorption and degradation of toluene were greater than for p-xylene under the same flow rate. The highest degradation rates for acetone, toluene, and p-xylene were $77.7,61.9$, and $55 \%$, respectively.

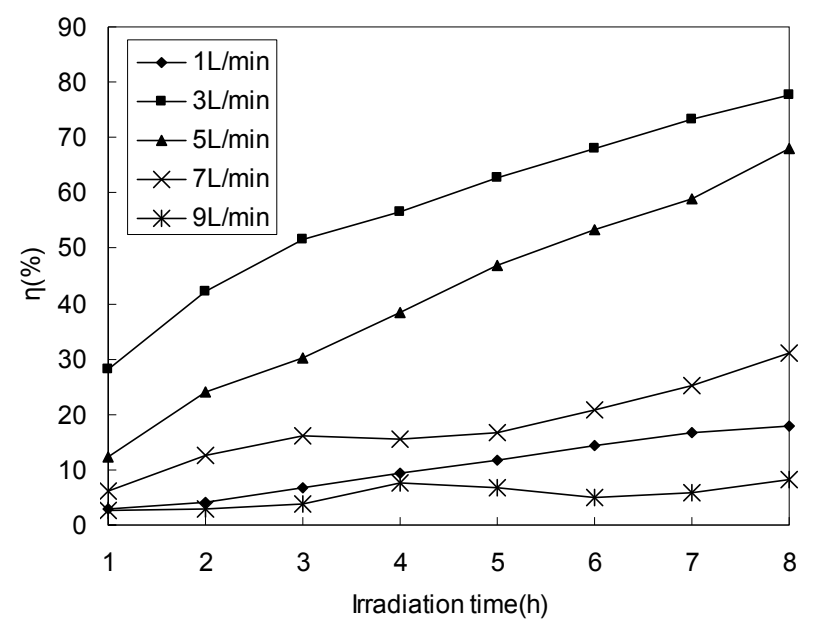

(a) Acetone 


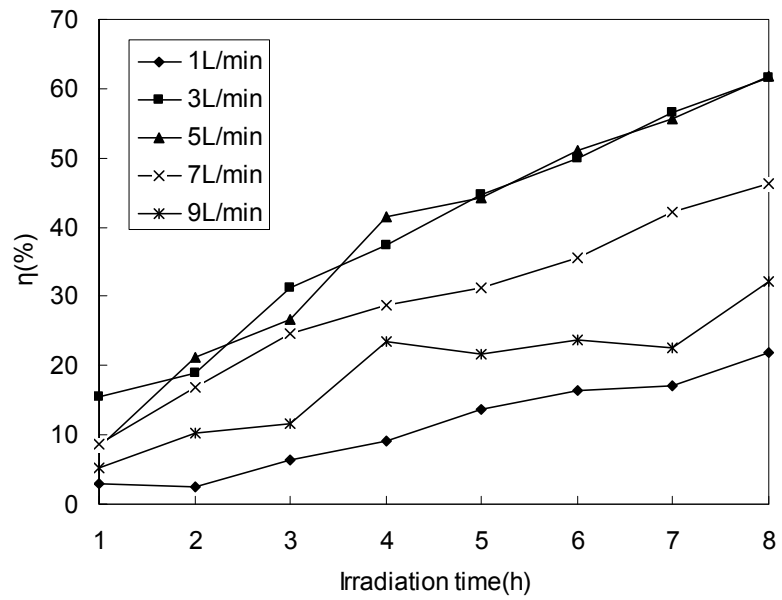

(b) Toluene

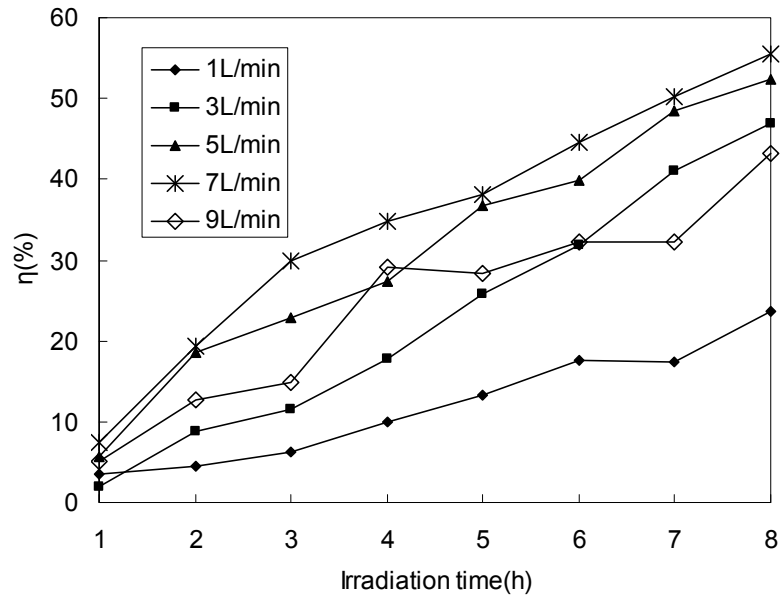

(c) P-xylene

Figure 15. Effect of flow rate on the degradation of acetone, toluene, and p-xylene by $\mathrm{TiO}_{2} / \mathrm{UV}$ processes.

The Langmuir-Hinshelwood (L-H) rate expression has been widely used to describe the gas-solid phase reaction for heterogeneous photocatalysis. Assuming that mass transfer is not the limiting step, and that the effect of intermediate products is negligible, then the reaction rate in a plug-flow reactor can be expressed as:

$$
r=-\frac{d C_{V O C}}{d t}=\frac{k K C}{1+K C}
$$


where $k$ and $K$ are the $\mathrm{L}-\mathrm{H}$ reaction rate constant and the $\mathrm{L}-\mathrm{H}$ adsorption equilibrium constant, respectively; and $\mathrm{t}$ is the time taken for ATP molecules to pass through the reactor. After integration of Equation (5) the following linear expression can be obtained:

$$
\frac{\ln \left(C_{\text {in }} / C_{\text {out }}\right)}{\left(C_{\text {in }}-C_{\text {out }}\right)}=\frac{k K T}{\left(C_{\text {in }}-C_{\text {out }}\right)}-K
$$

where $C_{\text {in }}$ and $C_{\text {out }}$ are the inlet and outlet concentrations of ATP, respectively; and $T$ is the recurrent time of VOCs in the reactor.

If the L-H model is valid, a plot of $\ln \left(C_{i n} / C_{\text {out }}\right) /\left(C_{i n}-C_{\text {out }}\right)$ versus $1 /\left(C_{i n}-C_{\text {out }}\right)$ should be linear. This was the case with our data (Fig. 16), and the linearity correlation coefficients of acetone, toluene and p-xylene were $0.9989,0.9995$ and 0.9992 , respectively. This result suggests that the reaction occurs on the photocatalyst surface through an $\mathrm{L}-\mathrm{H}$ mechanism and not in the gas phase.

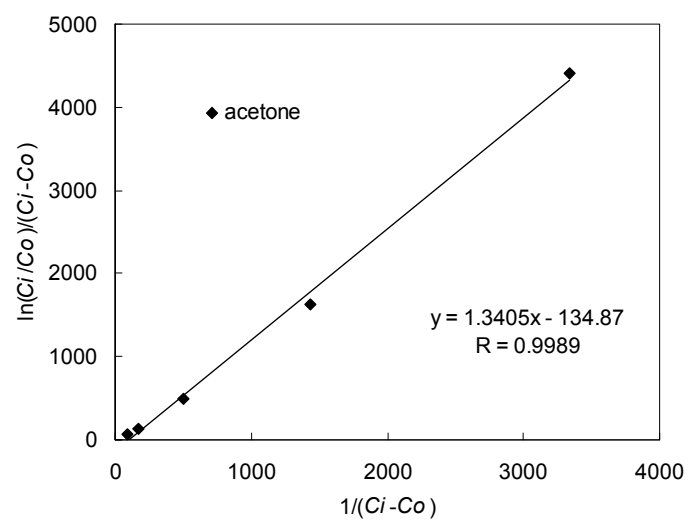

(a) Acetone

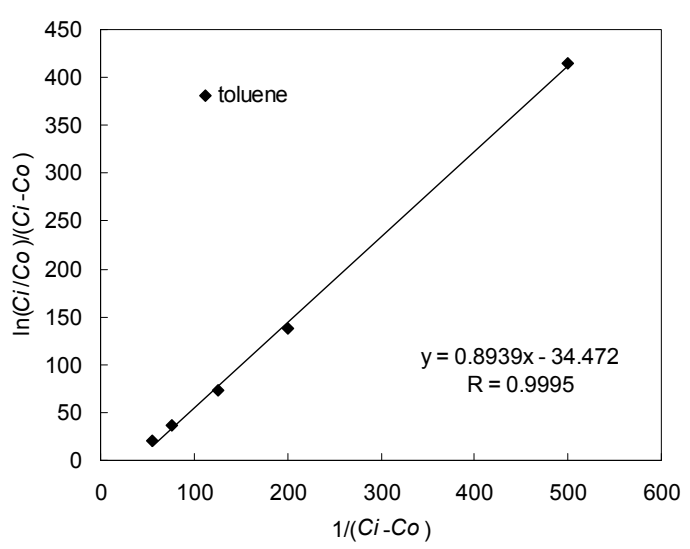

(b) Toluene 


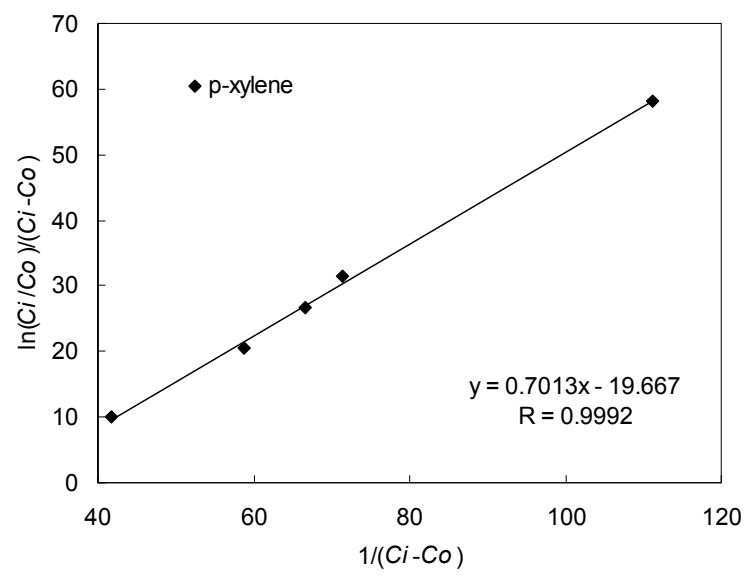

(c) P-xylene

Figure 16. Plot of $\ln \left(\mathrm{C}_{\text {in }} / \mathrm{C}_{\text {out }}\right) /\left(\mathrm{C}_{\text {in }}-\mathrm{C}_{\text {out }}\right)$ and $1 /\left(\mathrm{C}_{\text {in }}-\mathrm{C}_{\text {out }}\right)$.

\subsection{Degradation of Pure Individual VOCs and Their Mixture}

Gaseous-phase photo-degradation for pure individual VOCs (acetone, toluene, and pxylene) and their mixture was carried out in the continuous flow reactor system. The gas stream passed through the reactor at a flow rate of $5 \mathrm{~L} / \mathrm{min}$ and contained $0.1 \mathrm{~mol} / \mathrm{m}^{3}$ pure acetone, toluene, or p-xylene, or $0.3 \mathrm{~mol} / \mathrm{m}^{3}$ of their mixture. The gas residence time was $72 \mathrm{~s}$ in the reactor. The experiment was run for $8 \mathrm{hr}$, and samples were collected at hourly intervals.

Both acetone and p-xylene in the mixed gas degraded at much lower rates than their pure individual gases under the same conditions, just as shown in Fig. 17. However, the opposite trend was observed for toluene. Toluene has an unsymmetrical structure, which leads to instability and promotes adsorption and degradation of pollutant molecules on the catalyst surface according to the L-H mechanism. In addition, the byproducts of acetone and pxylene produced in the reaction could promote toluene degradation. In contrast, degradation of acetone and p-xylene in the mixed gas was reduced by competitive adsorption and catalysis of toluene. Among the pure gases and the mixture, acetone had the highest degradation efficiency. Furthermore, the efficiency of pure toluene degradation was lower than that of pure p-xylene degradation due to structural stability.

\subsection{Effect of gas temperature}

The effect of gas temperature on photo-catalytic degradation of gaseous toluene was investigated in the range of $25-50{ }^{\circ} \mathrm{C}$ (Fig. 18). The conditions were as follows: gas flow-rate of $1 \mathrm{~L} / \mathrm{min}$, relative humidity of $35 \%$, irradiation time of $8 \mathrm{~h}$, photo-catalyst of Ce-doped $\mathrm{TiO}_{2}$, and initial concentration of $0.1 \mathrm{~mol} / \mathrm{m}^{3}$. Degradation efficiency of toluene gradually 


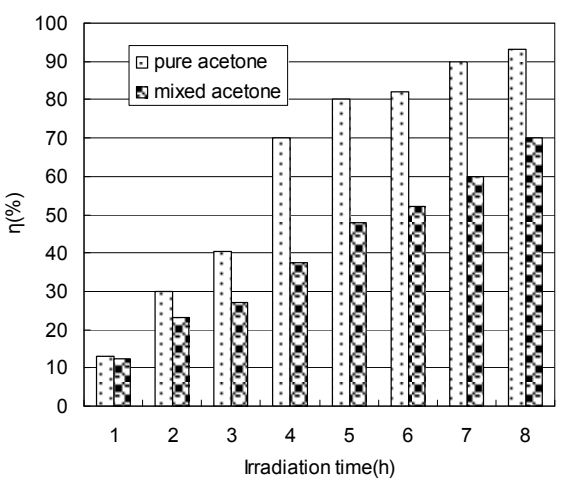

(a) Acetone

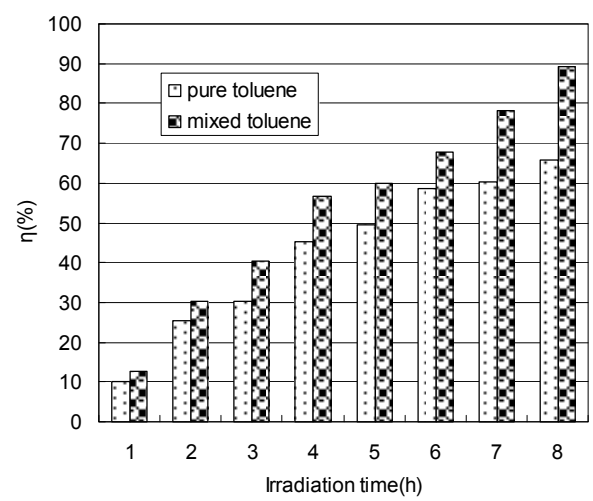

(b) Toluene

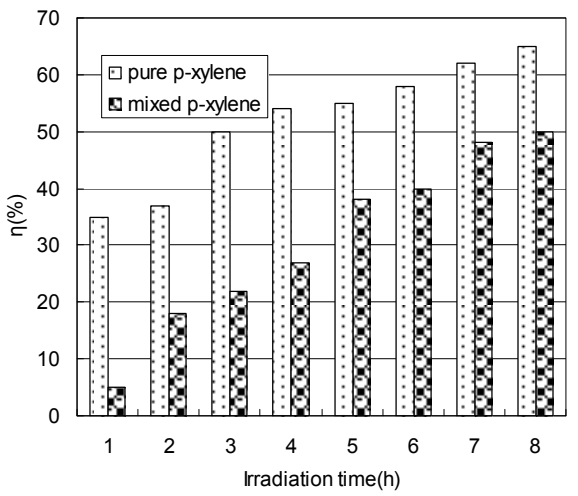

(c) P-xylene

Figure 17. Degradation with $\mathrm{H}_{2} \mathrm{O}_{2}$ of pure acetone, toluene, p-xylene, and their mixture. 
increased when gas temperature was below $45^{\circ} \mathrm{C}$, but decreased at $>45^{\circ} \mathrm{C}$. The increase in temperature would lead to the production of free radicals that could effectively collide with toluene molecules. Moreover, higher temperature may increase the oxidation rate of toluene at the interface. However, with increasing temperature, the adsorptive capacities of toluene on catalyst decreased, which led to the reduction of toluene removal efficiency.

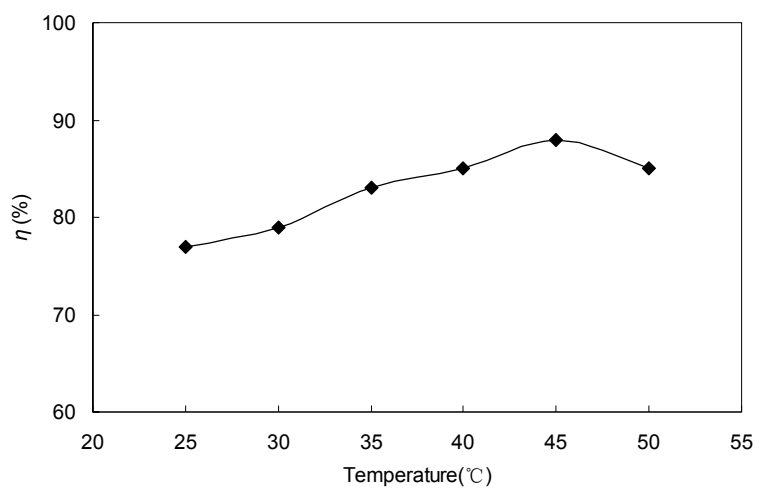

Figure 18. Effect of gas temperature on the photo-catalysis of toluene.

\subsection{Effect of photo-catalyst amount}

In photo-catalytic degradation of organic compounds, the optimal $\mathrm{TiO}_{2}$ concentration depends mainly on both the nature of the compounds and the reactor geometry. In this work, the influence of $\mathrm{TiO}_{2}$ amount on $\mathrm{HCHO}$ photo degradation was investigated. A set of gaseous experiments with different amount of $\mathrm{TiO}_{2}$ from 0 to $100 \mathrm{mg}$ was carried out at the $\mathrm{RH}$ of $35 \%$ and the initial $\mathrm{HCHO}$ concentration of $0.1 \mathrm{mg} / \mathrm{m}^{3}$. The degradation rates of $\mathrm{HCHO}$ for different amount $\mathrm{TiO}_{2}$ were presented in Fig. 19. The photo-catalytic degradation efficiency increased with increasing the amount of $\mathrm{TiO}_{2}$ when $\mathrm{TiO}_{2}$ amount was lower than $70 \mathrm{mg}$. When the $\mathrm{TiO}_{2}$ amount was more than $70 \mathrm{mg}$, the photo-catalytic degradation efficiency was decreased. So $70 \mathrm{mg}$ of $\mathrm{TiO}_{2}$ amount was the optional amount in our experiment. And the thickness of $70 \mathrm{mg}$ of $\mathrm{TiO}_{2}$ amount was about $0.2 \mathrm{~mm}$.

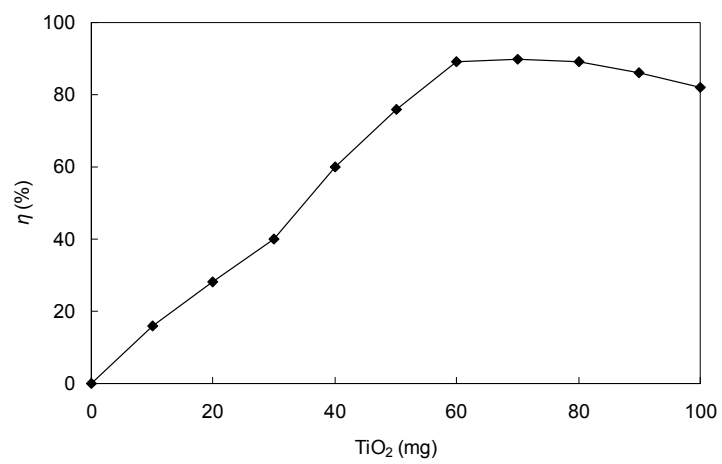

Figure 19. Effect of $\mathrm{TiO}_{2}$ amount on $\mathrm{HCHO}$ degradation 
At the same time, in our investigation, the effect of photo-catalyst concentration on the degradation of acetone in the gas flow was also analyzed in order to optimize the amount of $\mathrm{TiO}_{2}$. Different concentrations (15-105 mg/L) of $\mathrm{TiO}_{2}$ precursor sols were prepared by using different amounts of tetrabutyl orthotitanate. The conditions of the experiment were as follows: gas flow-rate of $1 \mathrm{~L} / \mathrm{min}$, relative humidity of $35 \%$, Ce-doped $\mathrm{TiO}_{2}$ as photo-catalyst, and irradiation time of $8 \mathrm{~h}$. BET surface area of the synthesized samples was tested (see Table 2). The results showed that BET surface area increased with increasing photo-catalyst amount.

\begin{tabular}{cccccccc}
\hline Sample concentration $(\mathrm{mg} / \mathrm{L})$ & 15 & 30 & 45 & 60 & 75 & 90 & 105 \\
\hline BET $\left(\mathrm{m}^{2} / \mathrm{g}\right)$ & 50.2 & 66.2 & 68.2 & 72.2 & 78.3 & 88.8 & 88.9 \\
\hline
\end{tabular}

Table 2. BET surface area for synthesized photo-catalyst.

Fig. 20 showed that the photo-catalytic degradation efficiency increased with increasing the amount of $\mathrm{TiO}_{2}$. It was suggested that increasing efficiency was due to the increase of the surface area. It could be observed that the degradation efficiency increased with increasing the amount of the catalyst until it reached a plateau at $90-105 \mathrm{mg} / \mathrm{L}$ of $\mathrm{TiO}_{2}$. This indicated that when the amount of $\mathrm{TiO}_{2}$ was overdosed, the surface area was saturated, and then the intensity of UV was attenuated because of decreased light penetration and increased light scattering.

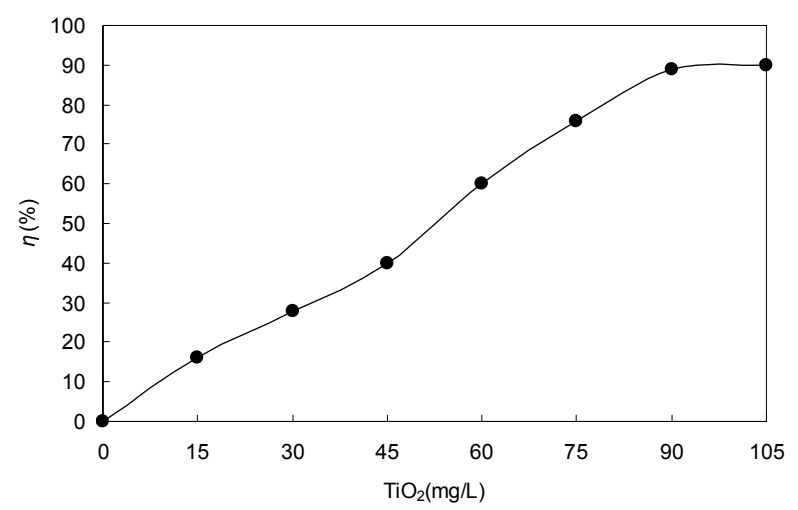

Figure 20. Effect of $\mathrm{TiO}_{2}$ amount on the photo-catalysis of acetone.

\subsection{Effect of relative humidity of air stream}

The effect of relative humidity $(0-60 \% \mathrm{RH})$ of air stream on $\mathrm{HCHO}$ decomposition was examined by adding water vapor to a fixed concentration of $\mathrm{HCHO}$. $\mathrm{TiO}_{2}$ photocatalyst was used in this experiment. Fig. 21 showed the experimental results at different relative humidity. The degradation rate increased with increasing relative humidity up to $35 \%$ and then started to decrease, which meant that $35 \%$ was the optimal humidity for photo-catalyst 
process under the experimental conditions. When the reaction time was $120 \mathrm{~min}$, the highest removal efficiency of $\mathrm{HCHO}$ was $60.2 \%$ when $\mathrm{RH}$ was $35 \%$.

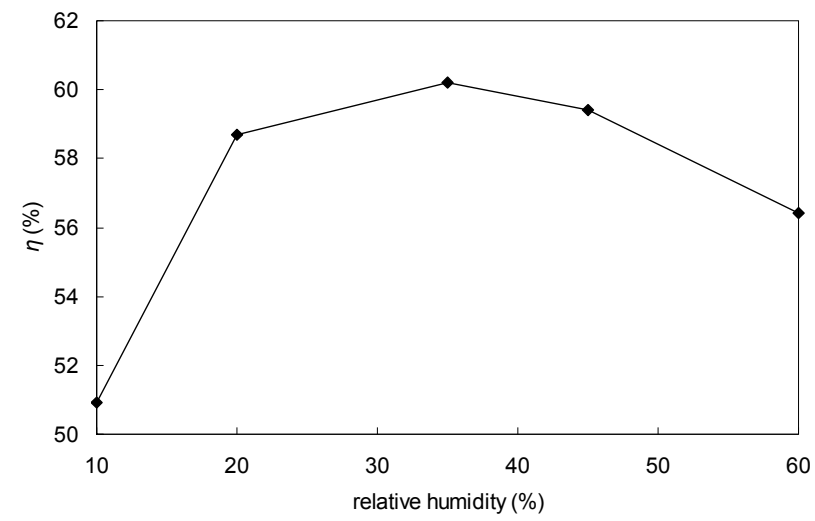

Figure 21. Effect of $\mathrm{RH}$ on decomposition of $\mathrm{HCHO}$.

The enhancement of photo-catalytic reaction rate is frequently found in the presence of water vapor because hydroxyl groups or water molecules can behave as hole traps to form surface-adsorbed hydroxyl radicals. In photo-catalyst process, the hydroxyl radicals formed on the illuminated $\mathrm{TiO}_{2}$ can not only directly attack $\mathrm{HCHO}$ molecules, but also suppress the electron-hole recombination. However, higher $\mathrm{RH}$ can be attributed to the competition for adsorption between $\mathrm{HCHO}$ and hydroxyl radicals, thus decrease the removal efficiency of $\mathrm{HCHO}$.

\subsection{Effect of oxygen concentration}

The effect of oxygen concentration on HCHO degradation was presented in Fig. 22.

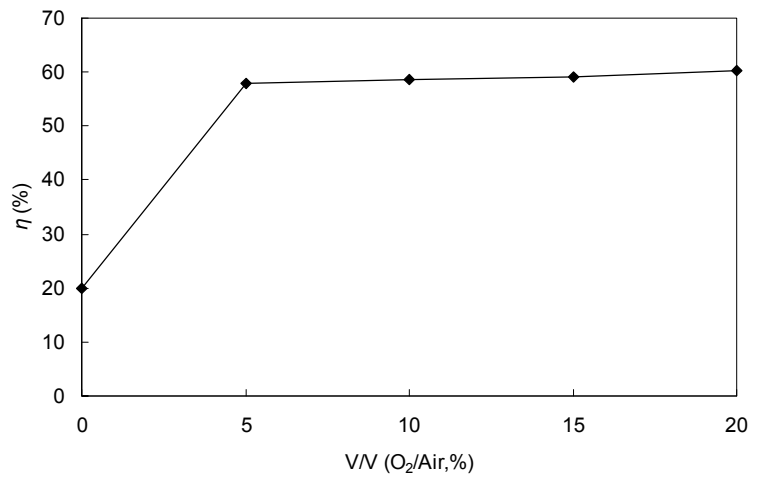

Figure 22. Effect of oxygen concentration on $\mathrm{HCHO}$ degradation. 
The results corresponded to the initial concentration of $0.1 \mathrm{mg} / \mathrm{m}^{3}$, relative humidity of $35 \%$ and reaction time of $120 \mathrm{~min}$. It is obvious that oxidation rates for $\mathrm{HCHO}$ increased with increasing $\mathrm{O}_{2}$ concentration under fixed conditions. As mentioned above, hydroxyl radical is an important factor to the $\mathrm{HCHO}$ photo-catalyst. At the same time, oxygen radical is also key factor for $\mathrm{HCHO}$ removal, which can react with $\mathrm{HCHO}$ on the $\mathrm{TiO}_{2}$ surface and turn $\mathrm{HCHO}$ into $\mathrm{CO}_{2}$ and $\mathrm{H}_{2} \mathrm{O}$.

\subsection{Mechanism of photo-catalytic degradation of VOCs}

The heterogeneous photo-catalytic process used in pollutant degradation involved the adsorption of pollutants on the surface sites, and the chemical reactions of converting pollutants into carbon dioxide and water. Activation of $\mathrm{TiO}_{2}$ is achieved through the absorption of a photon (hv) with ultra-band energy from UV irradiation source. This results in the promotion of an electron ( $\mathrm{e}^{-}$) from the valence band to the conduction band, with the generation of highly reactive positive holes $(\mathrm{h}+)$ in the valence band. This caused aggressive oxidation of the surface-adsorbed toxic organic pollutants and converts them into $\mathrm{CO}_{2}$ and water.

In the degradation of toluene or $\mathrm{p}$-xylene, the $\mathrm{OH} \bullet$ radicals attack the phenyl ring of toluene or p-xylene, and some products, such as phenol, benzaldehyde or benzoic acid, may be produced during the reaction, and they were converted into $\mathrm{CO}_{2}$ and $\mathrm{H}_{2} \mathrm{O}$ at the end (Fig. 23). We could also observe that acetone was easily destructed to $\mathrm{CO}_{2}$ and $\mathrm{H}_{2} \mathrm{O}$ by photocatalysts. By-products of toluene or p-xylene were detected by GC-MS, and involved phenol, benzaldehyde, aldehydes, alcohols, etc.
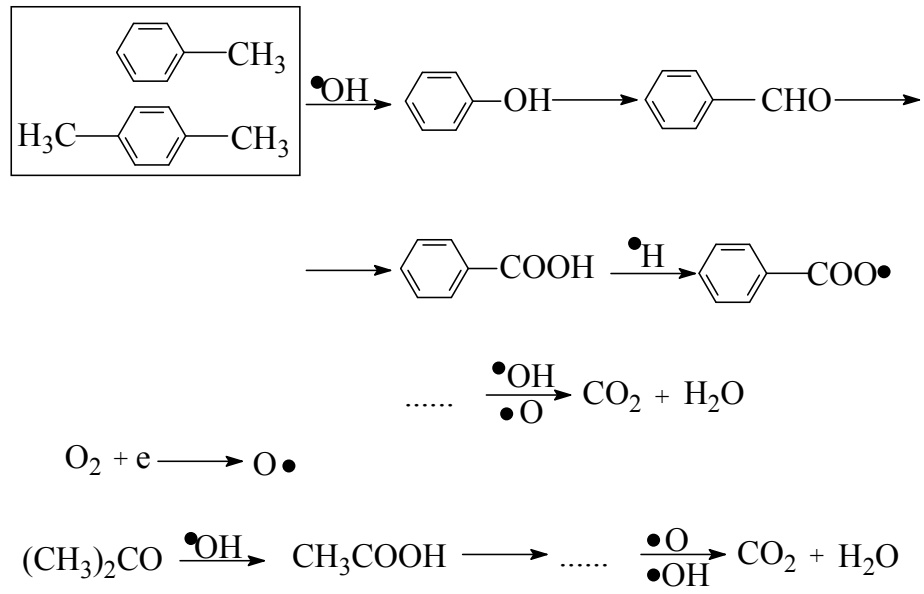

Figure 23. Suggested pathway for the photo-catalytic destruction of ATP.

The reaction rate constant $(k)$ was chosen as the basic kinetic parameter for ATP since it was important in determination of VOCs photo-catalytic activity. The first order kinetic equation: 


$$
\ln \left(\frac{C_{i}}{C_{o}}\right)=k \times t+b
$$

was used to fit experimental data in Fig. 24

where $C_{o}$ is the concentration of ATP remaining in the solution at $t$, and $C_{i}$ is the initial concentration at $\mathrm{t}=0$.

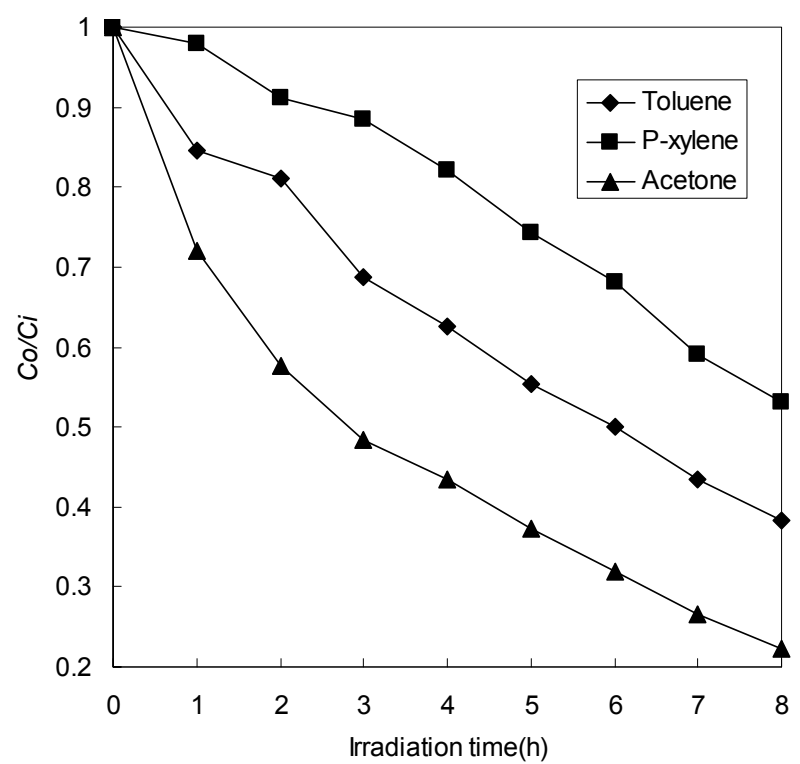

Figure 24. Kinetics of ATP degradation.

The variations in $\ln \left(\mathrm{C}_{\mathrm{i}} / \mathrm{C}_{0}\right)$ as a function of irradiation time are given in Fig. 25. Reaction rate constant (k), linearity correlation coefficient (R) and intercept (b) data for the photo-catalytic destruction of ATP are exhibited in Table 3. The k of ATP could be ordered as follows: $\mathrm{k}_{\text {Acetone }}>\mathrm{k}_{\text {Toluene }}>\mathrm{kP}$-xylene, meaning that the decomposition capability of acetone was the best. The reason was probably due to molecular structure and molecular weight. 


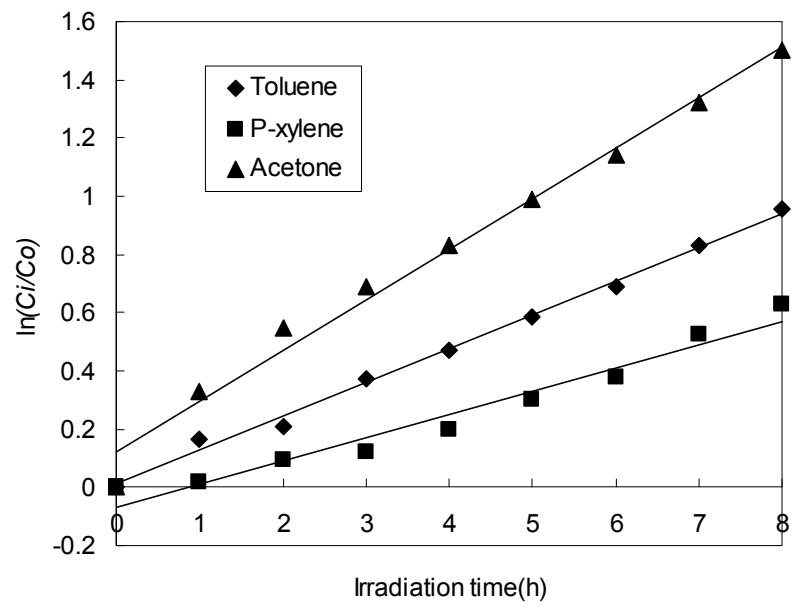

Figure 25. Relation between $\ln \left(\mathrm{C}_{\mathrm{i}} / \mathrm{C}_{\mathrm{o}}\right)$ and irradiation time, and linear fits for ATP.

\begin{tabular}{cccc}
\hline & $k\left(\mathrm{~h}^{-1}\right)$ & $R$ & $b$ \\
\hline Toluene & 0.1165 & 0.998 & 0.0102 \\
P-xylene & 0.0797 & 0.980 & -0.0668 \\
Acetone & 0.1742 & 0.993 & 0.12 \\
\hline
\end{tabular}

Table 3. Values of $k, R$ and $b$ for the photo-catalytic destruction of ATP.

During the HCHO decomposition by photo-catalytic processing, formic acid was identified as the intermediate from the photo-degradation of formaldehyde. In our experiment, ion chromatography (IC) was used to determine the byproducts by sampling the gas products into distilled water. The result in this study showed that formic acid was also found. The probably pathway of $\mathrm{HCHO}$ destruction was shown in Fig. 26. The related reactions of $\mathrm{HCHO}$ destruction were shown with equations (8)-(21).

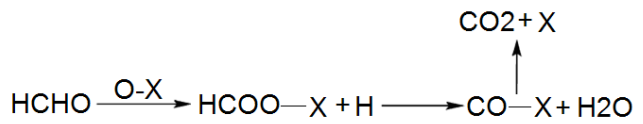

$$
X: \mathrm{TiO}_{2}, \mathrm{Ag} / \mathrm{TiO}_{2} \text { or } \mathrm{Ce} / \mathrm{TiO}_{2}
$$

Figure 26. Suggested pathway for the photo-catalytic destruction of $\mathrm{HCHO}$

$$
\begin{aligned}
& \mathrm{HCHO}+\mathrm{e} \longrightarrow \mathrm{H} \bullet+\mathrm{CHO}^{-} \\
& \mathrm{HCHO}+\mathrm{O} \bullet \longrightarrow \mathrm{OH} \bullet+\mathrm{CHO} \bullet \\
& \mathrm{HCHO}+\mathrm{OH} \longrightarrow \mathrm{H}_{2} \mathrm{O}+\mathrm{CHO} \bullet
\end{aligned}
$$




$$
\begin{aligned}
& \mathrm{HCHO}+\mathrm{OH} \longrightarrow \mathrm{HCOOH}+\mathrm{H} \bullet \\
& \mathrm{HCHO}+\mathrm{H} \bullet \longrightarrow \mathrm{H}_{2}+\mathrm{CHO} \bullet \\
& \mathrm{CHO} \bullet+\mathrm{H} \bullet \longrightarrow \mathrm{H}_{2}+\mathrm{CO} \\
& \mathrm{CHO} \bullet+\mathrm{O}_{2} \longrightarrow \mathrm{CO}_{2}+\mathrm{OH} \bullet \\
& \mathrm{CHO} \bullet+\mathrm{OH} \bullet \longrightarrow \mathrm{H}_{2} \mathrm{O}+\mathrm{CO} \\
& \mathrm{CHO} \bullet+\mathrm{HO}_{2} \bullet \longrightarrow \mathrm{OH} \bullet+\mathrm{H} \bullet+\mathrm{CO}_{2} \\
& \mathrm{CHO} \bullet+\mathrm{O} \bullet \longrightarrow \mathrm{OH} \bullet+\mathrm{CO} \\
& \mathrm{CHO} \bullet+\mathrm{O} \bullet \longrightarrow \mathrm{H} \bullet+\mathrm{CO}_{2} \\
& \mathrm{HCOOH}+\mathrm{OH} \bullet \longrightarrow \mathrm{H}_{2} \mathrm{O}+\mathrm{H} \bullet+\mathrm{CO}_{2} \\
& \mathrm{CO}+\mathrm{O} \bullet \longrightarrow \mathrm{CO}_{2} \\
& \mathrm{CO}+\mathrm{OH} \bullet \longrightarrow \mathrm{CO}_{2}+\mathrm{H} \bullet
\end{aligned}
$$

As mentioned in equation 7, $\mathrm{k}$ was the basic kinetic parameter for VOCs photo-catalytic activity. Fig. 27 showed the first order kinetic equation fitting the experimental data.

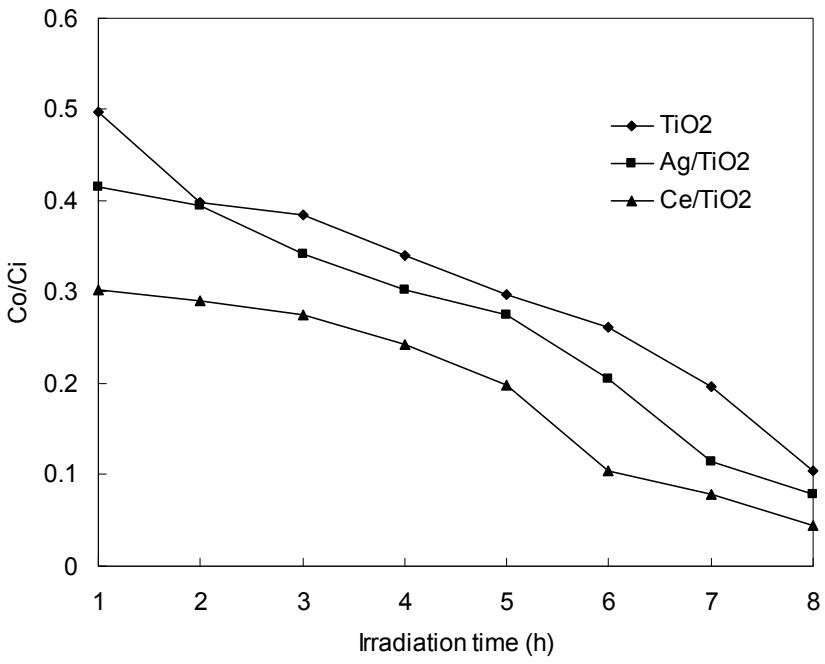

Figure 27. Kinetics of $\mathrm{HCHO}$ degradation. 
The variations in $\ln \left(\mathrm{C}_{\mathrm{i}} / \mathrm{C}_{\mathrm{o}}\right)$ as a function of reaction time were given in Fig. 28. The reaction rate constant for $\mathrm{TiO}_{2} 、 \mathrm{Ag} / \mathrm{TiO} \cdot \mathrm{Ce} / \mathrm{TiO}_{2}$ were $0.1871 \cdot 0.2302 、 0.2724$, respectively, which meant that $\mathrm{Ce} / \mathrm{TiO}_{2}$ had the best photo-catalytic abilities among the catalysts.

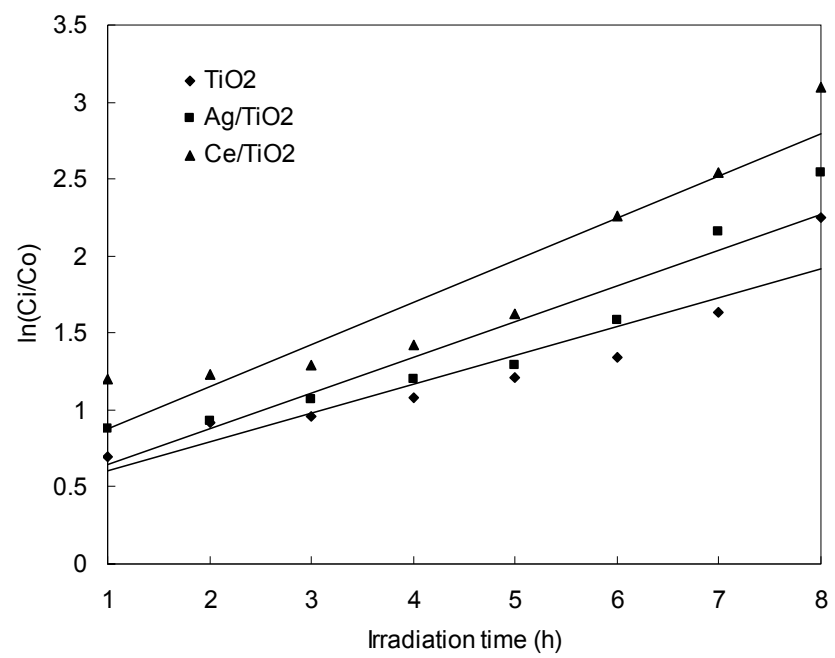

Figure 28. Relationship between $\ln \left(\mathrm{C}_{\mathrm{i}} / \mathrm{C}_{\mathrm{o}}\right)$ and reaction time.

\section{Conclusion}

In this chapter, nano-structured $\mathrm{TiO}_{2}, \mathrm{Ag}-\mathrm{TiO}_{2}$ and $\mathrm{Ce}-\mathrm{TiO}_{2}$ thin films coated on glass springs were prepared by sol-gel method at room temperature. Toluene, $\mathrm{p}$-xylene, acetone and formaldehyde were chosen as the model VOCs, the photo-catalytic degradation characters of them by $\mathrm{TiO}_{2} / \mathrm{UV}, \mathrm{TiO}_{2} /$ doped $\mathrm{Ag} / \mathrm{UV}$ and $\mathrm{TiO}_{2} /$ doped $\mathrm{Ce} / \mathrm{UV}$ was tested and compared. The effects of doped Ag/Ce ions, hydrogen peroxide, initial concentration, gas temperature, relative humidity of air stream, oxygen concentration, gas flow rate, UV light wavelength and photo-catalyst amount on decomposition of the pollutants by $\mathrm{TiO}_{2} / \mathrm{UV}$ were analyzed simultaneously. Furthermore, the mechanism of titania-assisted photo-catalytic degradation was analyzed, and the end product of the reaction using GC-MS analysis was also performed.

Results were as follows: (1) Characterization of this film by SEM and XRD showed it consisted of nanoparticles, and the crystalline phase was anatase. (2) Doped Ag or Ce ions could enhance the photo-catalyst ability. The degradation character of the photo-catalyst was in the order $\mathrm{Ce}-\mathrm{TiO}_{2}>\mathrm{Ag}-\mathrm{TiO}_{2}>\mathrm{TiO}_{2}$. (3) Hydrogen peroxide could promote the activation of catalyst, and toluene \& p-xylene degradation rate with hydrogen peroxide was higher than that without it. The final degradation rates of toluene and p-xylene using $\mathrm{H}_{2} \mathrm{O}_{2}$ were up to 97.1 and $95.4 \%$ after $8 \mathrm{~h}$, respectively. (4) The photo-catalytic degradation rates decreased with increasing VOCs initial concentration. Acetone was easiest to be destructed, 
while p-xylene was difficult to remove from gas flow. (5) The degradation efficiency gradually increased with gas temperature and $45^{\circ} \mathrm{C}$ had the best removal efficiency. (6) $35 \%$ was the optimal humidity for photo-catalyst process under the experimental conditions. (7) Higher concentration of oxygen was better for $\mathrm{HCHO}$ removal. (8) The flow rate greatly influenced the degradation rate. For acetone and toluene, the degradation rate was highest with a flow rate of $3 \mathrm{~L} / \mathrm{min}$. For $\mathrm{p}$-xylene, the degradation rate was highest when the flow rate was $7 \mathrm{~L} / \mathrm{min}$. The highest degradation rates for acetone, toluene and p-xylene were $77.7 \%, 61.9 \%$ and $55 \%$, respectively. (9) Illumination using a $254 \mathrm{~nm}$ light source was better than $365 \mathrm{~nm}$. (10) The photo-catalytic degradation efficiency increased with increasing the amount of $\mathrm{TiO}_{2}$ when $\mathrm{TiO}_{2}$ amount was lower than $70 \mathrm{mg}$. (11) In the gas mixture, acetone and p-xylene had much lower degradation rates than for their pure counterparts. The opposite trend was observed for toluene. Among acetone, toluene and p-xylene, the removal efficiency of acetone was highest both when pure and as a part of the gas mixture. (12) The photo-catalytic process used in pollutant degradation involved the adsorption of pollutants on the surface sites, and chemical reactions of converting pollutant into $\mathrm{CO}_{2}$ and $\mathrm{H}_{2} \mathrm{O}$ at the end. By-products of toluene or p-xylene were detected by GC-MS analysis, and involved phenol, benzaldehyde, aldehydes, alcohols, etc. The reaction rate constant (k) of ATP was sequenced $\mathrm{k}_{\text {Acetone }}>\mathrm{k}_{\text {Toluene }}>\mathrm{kP}$-xylene, meaning that the decomposition capability of acetone was the best, probably due to molecular structure and molecular weight. Formic acid was the main byproduct during the decomposition of $\mathrm{HCHO}$. The reaction rate constant $(\mathrm{k})$ of $\mathrm{TiO}_{2} 、 \mathrm{Ag} / \mathrm{TiO}_{2} \cdot \mathrm{Ce} / \mathrm{TiO}_{2}$ was sequenced $\mathrm{kCe} / \mathrm{TiO} 2>\mathrm{kAg}_{\mathrm{AiO}}>\mathrm{k}_{\mathrm{TiO}}$, meaning that $\mathrm{Ce} / \mathrm{TiO}_{2}$ had the best photo-catalytic abilities among the catalysts.

\section{Author details}

Wenjun Liang, Jian Li and Hong He

College of Environmental and Energy Engineering,

Beijing University of Technology, Beijing, China

\section{Acknowledgement}

This work was supported by National high technology research and development program of China (2011AA03A406) and Project of Beijing Municipal Education Commission (KM201110005011).

\section{References}

Akira F., Tata N.R., Donald A. (2000). Titanium dioxide photocatalysis, Journal of Photochemistry and Photobiology C: Photochemistry Reviews, Vol. 1,pp.1-21.

Alberici, R.M., Jardim, W.E. (1997). Photocatalytic destruction of VOCs in the gas-phase using titanium dioxide. Appl. Catal. B-Environ., Vol.14, pp. 55-68.

Ao C.H., Lee S.C., Yu J.Z., Xu J.H. (2004). Photodegradation of formaldehyde by photocatalyst TiO2: effects on the presences of NO, SO2 and VOCs. Appl. Catal. B., Vol.54, pp.41-50. 
Biard, P.F.; Bouzaza, A.; Wolbert, D. (2007). Photocatalytic Degradation of Two Volatile Fatty Acids in an Annular Plug-Flow Reactor; Kinetic Modeling and Contribution of Mass Transfer Rate. Environ. Sci. Technol., Vol.41, pp.2908-2914.

Boulamanti, A. K.; Philippopoulos, C. J. (2008). Photocatalytic degradation of methyl tert-butyl ether in the gas-phase: A kinetic study. J. Hazard Mater., Vol.160, pp. 83-87.

Boulamanti, A.K.; Korologos, C.A.; Philippopoulos, C.J. (2008). The rate of photocatalytic oxidation of aromatic volatile organic compounds in the gas-phase. Atmos. Environ., Vol.42, pp.7844-7850.

Bouzaza A., Vallet C., Laplanche A. (2006) Photocata-lytic degradation of some VOCs in the gas phase using an an-nular flow reactor. Determination of the contribution of mass transfer and chemical reaction steps in the photodegradation process. J. Photochem. Photobiol. A: Chem. Vol.177, pp.212-217.

Carp O., Huisman C.L., Reller A. (2004). Photoinduced reactivity of titanium dioxide. Prog. Solid State Chem., Vol.32, pp. 33-177.

Chatterjee D., Dasgupta S. (2005) Visible light induced photocatalytic degradation of organic pollutants. J. Photo-chem. Photobiol. C. Vol.6, pp.186-205.

Chen F., Pehkonen S.O., Ray M.B. (2002) Kinetics and mechanisms of UV-photodegradation of chlorinated organics in the gas phase. Water Res. Vol.36, pp.4203-4214.

Chen F., Yang Q., Pehkonen S.O., Ray M.B. (2004) Modeling of gas phase photodegradation of chlorinated VOCs. J. Air Waste Manage Assoc. Vol.54, pp.1281-1292.

Chen, X.B.; Mao, S.S. (2007). Titanium Dioxide Nanomaterials: Synthesis, Properties, Modifications, and Applications. Chem. Rev., Vol.107, pp. 2891-2959.

Collins J.J., Ness R., Tyl R.W., Krivanek N., Esmen N.A., Hall T.A. (2001). A Review of Adverse Pregnancy Outcomes and Formaldehyde Exposure in Human and Animal Studies. Regul. Toxicol. Pharm., Vol.34, pp.17-34.

Fujishima A., Zhang X.T. (2006). Titanium dioxide photocatalysis: present situation and future approaches, C. R. Chimie, Vol.9,pp.750-760.

Futamura S., Zhang A., Einaga H., Kabashima H. (2002) Involvement of catalyst materials in nonthermal plasma chemical processing of hazardous air pollutants. Catal. Today. Vol.72, pp.259-265.

González A. S., Martínez S. S. (2008) Study of the sono-photocatalytic degradation of basic blue 9 industrial textile dye over slurry titanium dioxide and influencing factors. Ultrason. Sonochem. Vol.15, pp. 1038-1042.

Hirakawa, T.; Koga, C.;Negishi, N.; Takeuchi, K.; Matsuzawa, S. (2009). An approach to elucidating photocatalytic reaction mechanisms by monitoring dissolved oxygen: Effect of $\mathrm{H} 2 \mathrm{O} 2$ on photocatalysis, Appl Catal B: Environ., Vol.87, pp. 46-55.

Holzer F., Roland U., Kopinke F.D. (2002) Combination of non-thermal plasma and heterogeneous catalysis for oxidation of volatile organic compounds Part 1 . Accessibility of the intra-particle volume. Appl. Catal. B: Environ. Vol.38, pp.163-181.

http://www.epa.gov/iaq/voc.html

Hu, Q.H.; Zhang, C.L.; Wang, Z.R.; Chen, Y.; Mao, K.H.; Zhang, X.Q.; Xiong, Y.L.; Zhu, M.J. (2008). Photodegradation of methyl tert-butyl ether (MTBE) by $\mathrm{UV} / \mathrm{H}_{2} \mathrm{O}_{2}$ and $\mathrm{UV} / \mathrm{TiO}_{2}$. J. Hazard Mater., Vol.154, pp.795-803. 
Jacoby W.A., Blake D.M., Noble R.D., Koval C.A. (1995). Kinetics of the Oxidation of Trichloroethylene in Air via Heterogeneous Photocatalysis. J. Catal., Vol.157, pp.87-96.

Jing L.Q., Xu Z.L., Sun X.J., Shang J., Cai W.M. (2001). The surface properties and photocatalytic activities of ZnO ultrafine particles. Appl. Surf. Sci., Vol.180, pp.308-314.

Kecske's T., Rasko'J., Kiss J. (2004). FTIR and mass spectrometric studies on the interaction of formaldehyde with $\mathrm{TiO}_{2}$ supported Pt and Au catalysts. Appl. Catal. A, Vol.273, pp.55-62.

Kim, S.B.; Hong, S.C. (2002). Kinetic study for photocatalytic degradation of volatile organic compounds in air using thin film $\mathrm{TiO}_{2}$ photocatalyst. Appl Catal B: Environ., Vol. 35, pp.305-315.

Li F.B., Li X.Z., Hou M.F., Cheah K.W., Choy W.C.H. (2005) Enhanced photocatalytic activity of $\mathrm{Ce}^{3+}-\mathrm{TiO}_{2}$ for 2-mercaptobenzothiazole degradation in aqueous suspension for odour control. Appl. Catal. A: Gen. Vol.285, pp.181-189.

Li, D.; Haneda, H.; Hishita, S.; Ohashi, N. (2005). Visible-light-driven nitrogen-doped $\mathrm{TiO}_{2}$ photocatalysts: effect of nitrogen precursors on their photocatalysis for decomposition of gas-phase organic pollutants. Mater. Sci. Eng. B., Vol.117, pp. 67-75.

Li, F.B.; Li, X.Z.; Ao, C.H.; Lee, S.C.; Hou, M.F. (2005).Enhanced photocatalytic degradation of VOCs using $\mathrm{Ln}^{3+}-\mathrm{TiO}_{2}$ catalysts for indoor air purification. Chemosphere, Vol.59, pp.787800.

Lin L., Zheng R.Y., Xie J.L., Zhu Y.X., Xie Y.C. (2007). Synthesis and characterization of phosphor and nitrogen co-doped titania. Appl. Catal. B., Vol.76, pp.196-202.

Liu H.M., Lian Z.W., Ye X.J., Shangguan W.F. (2005). Kinetic analysis of photocatalytic oxidation of gas-phase formaldehyde over titanium dioxide. Chemosphere, Vol.60, pp.630635.

Liu T.X., Li F.B., Li X.Z. (2008). $\mathrm{TiO}_{2}$ hydrosols with high activity for photocatalytic degradation of formaldehyde in a gaseous phase. J. Hazard. Mater., Vol.152, pp.347-355.

Lu Y.W., Wang D.H., Ma C.F., Yang H.C. (2010). The effect of activated carbon adsorption on the photocatalytic removal of formaldehyde. Building and Environment, Vol.45, pp.615-621.

Mohseni, M. (2005). Gas phase trichloroethylene (TCE) photooxidation and byproduct formation: photolysis vs. titania/silica based photocatalysis. Chemosphere, Vol.59, pp. 335342.

Obee, T.N. (1995). $\mathrm{TiO}_{2}$ Photocatalysis for Indoor Air Applications: Effects of Humidity and Trace Contaminant Levels on the Oxidation Rates of Formaldehyde, Toluene, and 1, 3Butadiene. Environ. Sci. Technol., Vol.29, pp.1223-1231.

Ogata A., Einaga H., Kabashima H., Futamura S., Kushi-yama S., Kim H. H. (2003) Effective combination of nonthermal plasma and catalysts for decomposition of benzene in air. Appl. Catal. B: Environ. Vol.46, pp.87-95.

Ohno T., Tsubota T., Nakamura Y., Sayama K.(2005). Preparation of S, C cation-codoped $\mathrm{SrTiO}_{3}$ and its photocata-lytic activity under visible light. Appl. Catal. A., Vol.288, pp.74-79.

Ohtani B. (2010). Photocatalysis A to Z-What we know and what we do not know in a scientific sense, Journal of Photochemistry and Photobiology C: Photochemistry Reviews, Vol.11, pp.157-178.

Olmez T. (2008) Photocatalytic Treatment of phenol with visible light irradiation. Fresen. Environ. Bull. Vol.17, pp.1796-1802. 
P'erez, M.; Torrades, F.; Garc'1a-Hortal, J.A.; Dom 'enech, X.; Peral, J. (2002). Removal of organic contaminants in paper pulp treatment effluents under Fenton and photo-Fenton conditions. Appl. Catal. B: Environ., Vol.36, pp.63-74.

Parmar, G.R., Rao N.N. (2009). Emerging Control Technologies for Volatile Organic Compounds, Critical Reviews in Environmental Science and Technology, Vol.39, pp.41-78.

Sakthivel, S.; Kisch, H. (2003). Photocatalytic and photoelectrochemical properties of nitrogendoped titanium dioxide. Chem. Phys. Chem., Vol.4, pp. 487-490.

Sano T., Negishi N., Takeuchi K., Matsuzawa S. (2004). Degradation of toluene and acetaldehyde with Pt-loaded $\mathrm{TiO}_{2}$ catalyst and parabolic trough concentrator. Solar Energy, Vol.77, pp.543-552.

Shan G.B., Yan S., Tyagi R.D., Surampalli R.Y., Zhang T.C. (2009). Applications of Nanomaterials in Environmental Science and Engineering: Review, Practice Peri-odical of Hazardous, Toxic, and Radioactive Waste Management, Vol.13, pp.110-119.

Shang J., Du Y.G., Xu Z.L. (2002). Photocatalytic oxidation of heptane in the gas-phase over TiO2.Chemosphere, Vol.46, pp.93-99.

Shiraishi F., Yamaguchi S., Ohbuchi Y. (2003). A rapid treatment of formaldehyde in a highly tight room using a photocatalytic reactor combined with a continuous adsorption and desorption apparatus. Chem. Eng. Sci., Vol.58, pp.929-934.

Sleiman, M.; Conchon, P.; Ferronato, C.; Chovelon, J.M. (2009). Photocatalytic oxidation of toluene at indoor air levels (ppbv): Towards a better assessment of conversion, reaction intermediates and mineralization. Appl Catal B: Environ., Vol.86, pp.159-165.

Somekawa S., Kusumoto Y., Ikeda M., Ahmmad B., Horie Y. (2008). Fabrication of N-doped $\mathrm{TiO}_{2}$ thin films by laser ablation method: Mechanism of $\mathrm{N}$-doping and evaluation of the thin films. Catal. Commun., Vol.9, pp.437-440.

Song L., Qiu R.L., Mo Y.Q., Zhang D.D., Wei H., Xiong Y. (2007). Photodegradation of phenol in a polymer-modified $\mathrm{TiO} 2$ semiconductor particulate system under the irradiation of visible light. Catal. Commun., Vol.8, pp.429-433.

Sun R.B., Xi Z.G., Chao F.H., Zhang W., Zhang H.S., Yang D.F. (2007) Decomposition of lowconcentration gas-phase toluene using plasma-driven photocatalyst reactor. Atmos. Environ. Vol.41, pp.6853-6859.

Tanada S., Kawasaki N., Nakamura T., Araki M., Isomura M. (1999). Removal of Formaldehyde by Activated Carbons Containing Amino Groups. J. Colloid. Interf. Sci., Vol.214, pp.106-108.

Tokumura, M.; Nakajima, R.; Znad, H. T.; Kawase, Y. (2008). Chemical absorption process for degradation of VOC gas using heterogeneous gas-liquid photocatalytic oxidation: Toluene degradation by photo-Fenton reaction. Chemosphere, Vol.73, pp. 768-775.

Venkatachalam N., Palanichamy M., Arabindoo B., Mu-rugesan V. (2007). Alkaline earth metal doped nanoporous $\mathrm{TiO}_{2}$ for enhanced photocatalytic mineralisation of bisphenol-A. Catal. Commun., Vol.8, pp.1088-1093.

Vincenzo A., Marta L., Leonardo P., Javier S. (2006). The combination of heterogeneous photocatalysis with chemical and physical operations: A tool for improving the photoprocess performance, Journal of Photochemistry and Photobiology C: Photochemistry Reviews, Vol.7,pp.127-144. 
Wang J.H., Ray M.B. (2000) Application of ultraviolet photooxidation to remove organic pollutants in the gas phase. Sep. Purif. Technol. Vol.19, pp.11-20.

Wang Y.Y., Zhou G.W., Li T.D., Qiao W.T., Li Y.J. (2009) Catalytic activity of mesoporous $\mathrm{TiO}_{2}$ ${ }_{x} N_{x}$ photocatalysts for the decomposition of methyl orange under solar simulated light. Catal. Commun. Vol.10, pp.412-415.

Wang, X.Q.; Zhang, G.L.; Zhang, F.B.; Wang, Y. (2006). Study integration about Photocatalytic degradation of gaseous benzene in atmosphere by using $\mathrm{TiO}_{2}$ photocatalyst. Chemical Research and Application, Vol.18, pp.344-348.

Wu C.D., Xu H., Li H.M., Chu J.Y., Yan Y.S., Li C.S. (2007) Photocatalytic decolorization of methylene blue via Ag-deposited $\mathrm{BiVo}(4)$ under UV-light irradiation. Fresen. Environ. Bull. Vol.16, pp. 242-246.

Xu Y.H., Chen H.R., Zeng Z.X., Lei B. (2006). Investigation on mechanism of photocatalytic activity enhancement of nanometer cerium-doped titania. Appl. Surf. Sci., Vol.252, pp.8565-8570.

Yang S.X., Zhu W.P., Jiang Z.P., Chen Z.X., Wang J.B. (2006). The surface properties and the activities in catalytic wet air oxidation over $\mathrm{CeO}_{2}-\mathrm{TiO}_{2}$ catalysts. Appl. Surf. Sci., Vol.252, pp.8499-8505.

Yang X., Xu L.L., Yu X.D., Guo Y.H. (2008) One-step preparation of silver and indium oxide co-doped $\mathrm{TiO}_{2}$ photo-catalyst for the degradation of rhodamine B. Catal. Commun. Vol.9, pp.1224-1229.

Yi Z., Wei W., Lee S., Gao J.H. (2007). Photocatalytic performance of plasma sprayed Ptmodified $\mathrm{TiO}_{2}$ coatings under visible light irradiation. Catal. Commun., Vol.8, pp.906-912.

Yu J.C., Yu J.G., Ho W.K., Zhang L.Z. (2001). Preparation of highly photocatalytic active nanosized $\mathrm{TiO}_{2}$ particles via ultrasonic irradiation. Chem. Commun., Vol.19, pp.1942-1943.

Yu J.G., Yu J.C., Cheng B., Hark S.K., Iu K. (2003). The effect of F--doping and temperature on the structural and textural evolution of mesoporous $\mathrm{TiO}_{2}$ powders. J. Solid State Chem., Vol.174, pp.372-380.

Zhang C.B., He H. (2007). A comparative study of $\mathrm{TiO}_{2}$ supported noble metal catalysts for the oxidation of formaldehyde at room temperature. Catalysis Today, Vol.126, pp.345-350.

Zhang C.B., He H., Tanaka K.I. (2005). Perfect catalytic oxidation of formaldehyde over a $\mathrm{Pt} / \mathrm{TiO}_{2}$ catalyst at room temperature. Catal. Commun., Vol.6, pp.211-214.

Zhang C.B., He H., Tanaka K.I. (2006). Catalytic performance and mechanism of a $\mathrm{Pt} / \mathrm{TiO}_{2}$ catalyst for the oxidation of formaldehyde at room temperature. Appl. Catal. B., Vol.65, pp.37-43.

Zhang, P.Y.; Liang, F.Y.; Yu, G.; Chen, Q.; Zhu, W.P. (2003). A comparative study on decomposition of gaseous toluene by $\mathrm{O}_{3} / \mathrm{UV}, \mathrm{TiO}_{2} / \mathrm{UV}$ and $\mathrm{O}_{3} / \mathrm{TiO}_{2} / \mathrm{UV}$. J. Photoch. Photobio. A., Vol.156, pp.189-194.

Zou, L.D.; Luo, Y.G.; Hooper, M.; Hu, Eric. (2006). Removal of VOCs by photocatalysis process using adsorption enhanced $\mathrm{TiO}_{2}-\mathrm{SiO}_{2}$ catalyst. Chem. Eng. Process., Vol.45, pp.959964.

Zuo G.M., Cheng Z.X., Chen H., Li G.W., Miao T. (2006) Study on photocatalytic degradation of several volatile or-ganic compounds. J. Hazard. Mater. Vol.128, pp.158-163. 